\title{
RESSONÂNCIA DE PLASMON DE SUPERFÍCIE LOCALIZADO E APLICAÇÃO EM BIOSSENSORES E CÉLULAS SOLARES
}

\author{
Jacqueline Ferreira Leite Santos*, Marcos José Leite Santos\#, Anderson Thesing, Fabiele Tavares, Jordana Griep e Marcos \\ Renan Flores Rodrigues \\ Instituto de Química, Universidade Federal do Rio Grande do Sul, 91501-970 Porto Alegre - RS, Brasil
}

Recebido em 01/02/2016; aceito em 02/05/2016; publicado na web em 15/07/2016

\begin{abstract}
LOCALIZED SURFACE PLASMON RESSONANCE APPLIED TO BIOSENSORS AND SOLAR CELLS. Within the last decades, the research on nanoparticles presenting localized surface plasmon resonance has increased constantly. In these materials, the interaction between electrons and incident light results in charge separation, enhancement of the electromagnetic field on the nanoparticles surface and in unique optical properties. Although many metals such as gold, silver, copper and aluminum present localized surface plasmon resonance within the visible range, gold and silver are the most commonly studied metals, due to the chemical inertia of gold and intense plasmon resonance from silver. In this review, we provide a description of the origin of localized surface plasmon resonance through the works developed by Mie, Maxwell and Maxwell-Garnett and a description of many examples of application of plasmonic nanoparticles on biosensors and solar cells, detailing the contribution of these plasmonic nanoparticles on the performance of these devices.
\end{abstract}

Keywords: LSPR; Localized Surface Plasmon Resonance; biosensor; solar cell.

\section{INTRODUÇÃO}

Nos últimos 20 anos o interesse por nanopartículas metálicas (NPs-M) tem aumentado constantemente devido a sua ampla variedade de aplicações. ${ }^{1-8}$ Vários grupos de pesquisa têm estudado desde nanopartículas isoladas de cerca de $1 \mathrm{~nm}$ até nanopartículas de centenas de nanômetros, assim como seus aglomerados, buscando entender seu comportamento óptico e catalítico. Adicionalmente, a literatura descreve a constante busca por metodologias de síntese cada vez mais simples, de baixo custo e com alta reprodutibilidade. O comportamento óptico de nanopartículas metálicas tem fascinado a humanidade há vários séculos através de obras de arte, mesmo antes que a palavra nanotecnologia fosse utilizada. ${ }^{9} \mathrm{Um}$ dos exemplos mais conhecidos é a Taça de Lycurgus (século 4 d.C), que tem em sua composição nanopartículas de ouro (NPAu). ${ }^{10}$ No entanto, foi somente em 1857 que as NPs-M receberam maior atenção devido aos estudos de Michael Faraday sobre o efeito da interação da luz em uma solução coloidal de NPAu obtida através da redução do cloreto de ouro pelo fósforo. ${ }^{11,12}$ Deste então, o interesse nestas NPs tem aumentado e novas metodologias de síntese e caracterização têm sido desenvolvidas, possibilitando grande controle de tamanho e formato. ${ }^{13-15} \mathrm{~A}$ pesquisa nesta área foi enriquecida pela compreensão do efeito da ressonância de plasmon de superfície localizado (LSPR), que explica o comportamento óptico destes materiais. Mie foi o primeiro a elucidar a origem das cores nestas estruturas e sua teoria foi posteriormente complementada com os modelos de Maxwell-Garnett que explicavam a interação de NPs-M com o meio. Estes estudos proporcionaram uma ampla visão quanto as possíveis aplicações das NPs-M, sendo atualmente empregada no desenvolvimento de novos materiais como células solares, biossensores e catalisadores. Nesta revisão, serão abordados os embasamentos teóricos envolvidos no efeito LSPR de NPs-M, destacando a aplicação destas nanoestruturas no desenvolvimento de biossensores e células solares.

*e-mail: jacqueline.ferreira@ufrgs.br

\#e-mail alternativo: mjls@ufrgs.br

\section{ASPECTOS TEÓRICOS SOBRE O LSPR}

\section{Teoria de Mie}

Para que o LSPR pudesse ser compreendido, foi necessário que houvessem avanços científicos relacionados a compreensão da composição e do comportamento eletromagnético da luz. Estes avanços tiveram início em 1820, quando o físico e químico dinamarquês Hans Christian Orsted, através de observações experimentais da deflexão de uma bússola nas proximidades de um fio condutor permeado por uma corrente elétrica, deu um passo importante para a unificação da eletricidade e do magnetismo (até então os fenômenos elétricos e magnéticos eram estudados separadamente). ${ }^{16}$ Posteriormente, em 1865 o físico e matemático escocês James Clerk Maxwell desenvolveu a teoria do eletromagnetismo, que corroborava os fenômenos observados de interação entre a eletricidade e o magnetismo. ${ }^{17}$ As equações propostas por Maxwell permitiram explicar com clareza diversos fenômenos, permitindo classificar a luz como sendo uma onda eletromagnética, caracterizada por oscilações de campos elétricos e magnéticos (perpendiculares entre si) em função do tempo. O trabalho de Maxwell constitui a base do eletromagnetismo clássico, sendo referenciado em inúmeras aplicações práticas, como no desenvolvimento das telecomunicações. Em 1888, Hertz demonstrou que cargas em oscilações irradiavam ondas eletromagnéticas e que estas poderiam ser coletadas por antenas a distâncias afastadas do local onde eram geradas, o que provou a onda eletromagnética apresentada na teoria de Maxwell. ${ }^{18,19}$ Em 1857, paralelamente ao trabalho de Maxwell para o eletromagnetismo, o físico e químico inglês Michael Faraday trabalhava na interação da luz com soluções coloidais, e através de dados empíricos descreveu a dependência das colorações dos coloides com a concentração e tamanho das partículas presentes na solução. ${ }^{11}$ Suas contribuições, somadas ao estudo das equações do eletromagnetismo aplicadas nas propagações das ondas eletromagnéticas a grandes distâncias, elevou o interesse na compreensão da interação dos campos eletromagnéticos com a matéria para explicar os fenômenos de transmissão, reflexão, espalhamento e absorção da luz. 
Em 1908 Mie apresentou uma resolução satisfatória para as equações de Maxwell, através de um extenso trabalho matemático realizado a mão, no qual considerou uma onda eletromagnética interagindo com uma esfera condutora. ${ }^{20-24}$ Neste trabalho, Mie condicionou o sistema mediante as seguintes condições de contorno: uma onda eletromagnética polarizada num dado plano incidindo sobre uma esfera homogênea circundada por um meio dielétrico real, com equivalente índice de refração real (Re). Considerando a esfera condutora, deve ser avaliado o fenômeno de absorção da onda eletromagnética, já que a função dielétrica de um condutor é complexa (possui uma componente imaginária, Im) e, por sua vez, tem índice de refração complexo, o qual é função da frequência da onda eletromagnética incidente. As soluções das equações para as seções de choque $\left(\sigma_{\text {ext }} \mathrm{e}\right.$ $\sigma_{\text {esp }}$ ) de extinção (absorção + espalhamento) e de espalhamento das nanopartículas levam a séries de múltiplos dipolos induzidos, em que o indexador L denota o comportamento do campo da onda sobre a partícula, sendo $\mathrm{L}=1$ para dipolar, $\mathrm{L}=2$ quadripolar. As soluções para $\sigma_{\text {ext }}$ e $\sigma_{\text {esp }}$ estão resumidas através das Equações 1 e 2.20-23,25,26

$$
\begin{gathered}
\sigma_{e x t}=\frac{2}{x^{2}} \sum_{L-1}^{\infty}(2 \mathrm{~L}+1) \operatorname{Re}\left(a_{L}+b_{L}\right) \\
\sigma_{e s p}=\frac{2}{x^{2}} \sum_{L-1}^{\infty}(2 \mathrm{~L}+1)\left(\left|a_{L}\right|^{2}+\left|b_{L}\right|^{2}\right)
\end{gathered}
$$

Sendo:

$$
\sigma_{a b s}=\sigma_{e x t}-\sigma_{e s p}
$$

Os valores de $\mathrm{a}_{\mathrm{L}}$ e $\mathrm{b}_{\mathrm{L}}$ são descritos através das Equações 4 e 5 .

$$
\begin{aligned}
& a_{L}=\frac{m \psi_{L}(m x) \psi_{L}^{\prime}(x)-\psi_{L}^{\prime}(m x) \psi_{L}(x)}{\psi_{L}(m x) \xi_{L}^{\prime}(x)-\mathrm{m} \xi_{L}(m x) \psi_{L}^{\prime}(x)} \\
& b_{L}=\frac{\psi_{L}(m x) \psi_{L}^{\prime}(x)-\psi_{L}^{\prime}(m x) m \psi_{L}(x)}{\psi_{L}(m x) \xi_{L}^{\prime}(x)-\psi_{L}^{\prime}(m x) m \xi_{L}(x)}
\end{aligned}
$$

$\mathrm{m}=\mathrm{n}_{\mathrm{p}} / \mathrm{n}_{\mathrm{m}}$, sendo $\mathrm{n}_{\mathrm{p}} \mathrm{o}$ índice de refração da partícula e $\mathrm{n}_{\mathrm{m}} \mathrm{o}$ índice de refração real do meio que circunda a partícula; $\psi_{\mathrm{L}}$ e $\xi_{\mathrm{L}}$ são respectivamente funções cilindricas de primeira e segunda ordem de Ricatti-Bessel.

Considerando apenas as nanopartículas que possuem $2 \mathrm{r}<<\lambda$ ou aproximadamente $2 \mathrm{r}<\lambda_{\text {máx }} / 10$, a interação da onda eletromagnética com a nanopartícula cria campos do tipo dipolo induzido, e assim, somente os primeiros termos das séries expandidas são necessários. Utilizando esta aproximação, conhecida como aproximação quase estática, uma vez que o campo elétrico da onda eletromagnética incidente é considerado como sendo estático sobre a nanopartícula num determinado período, Mie obteve a expressão descrita na Equação 6. ${ }^{27,28}$

$$
\sigma_{\text {ext }}=9 \frac{\omega}{c} \varepsilon_{\mathrm{m}}^{3 / 2} \mathrm{~V} \frac{\varepsilon_{2}(\omega)}{\left[\varepsilon_{1}(\omega)+2 \varepsilon_{m}\right]^{2}+\varepsilon_{2}(\omega)^{2}}
$$

em que $\mathrm{V}$ é o volume da partícula, $\omega$ é a frequência angular da luz extinta, c é a velocidade da luz, e $\varepsilon_{\mathrm{m}}$ e $\varepsilon(\omega)=\varepsilon_{1}(\omega)+i \varepsilon_{2}(\omega)$ são as funções dielétricas do meio e do material, respectivamente. A condição de ressonância é atingida quando $\varepsilon_{1}(\omega)=-2 \varepsilon_{\mathrm{m}}$ e somente se $\varepsilon_{2}$ for fracamente dependente de $\omega$.

A incidência de um campo elétrico homogêneo sobre a partícula metálica, resulta no deslocamento dos elétrons desta partícula no sentido contrário ao campo elétrico da onda incidente. Este deslocamento das cargas promove a indução de um dipolo elétrico na partícula.

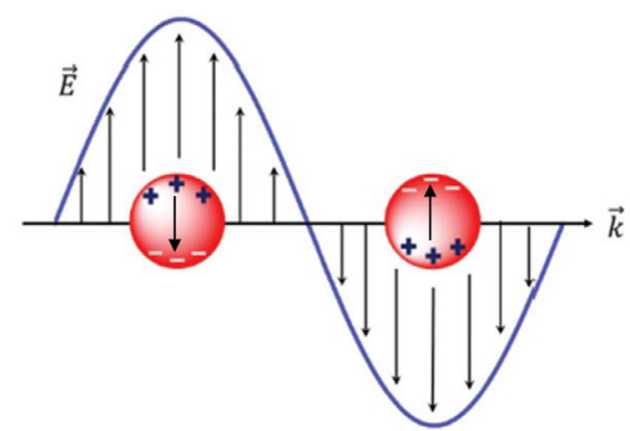

Figura 1. Origem de um dipolo elétrico induzido e efeito da força restauradora devido à separação de cargas nas nanopartículas metálicas. Adaptada da ref. 25 com permissão da American Chemical Society

O dipolo induzido promove o aparecimento de um campo elétrico restaurador na partícula, o qual tem a função de restaurar o equilíbrio dado pela distorção das cargas. Esta força restauradora e a indução do dipolo, quando acopladas, geram a ressonância plasmônica. ${ }^{29} \mathrm{~A}$ Figura 1 ilustra o dipolo elétrico induzido e a força restauradora criada devido a separação de cargas na partícula.

Considerando apenas a indução de dipolos elétricos nas nanopartículas, e que estes dipolos não interajam com possíveis dipolos elétricos de nanopartículas vizinhas, para aproximação quase estática $(2 \mathrm{r}<$ $\lambda_{\text {máx }}(10)$, a teoria agregada de parâmetros intrínsecos às nanopartículas, como ajustes na função dielétrica da nanopartícula, parâmetros de correção geométrica, ${ }^{27}$ revelou-se uma boa resposta de modelamento frente aos dados obtidos teórica e experimentalmente como observado por Michael Faraday. ${ }^{11}$ No entanto, a teoria de Mie não confirma os dados experimentais obtidos para os espectros de extinção em sua totalidade. A teoria é bem sucedida para partículas isoladas umas das outras e para partículas com poucas dezenas de nanômetros, ${ }^{21,23}$ uma vez que estabelece condições de contorno relacionadas com o tamanho da nanopartícula e da onda eletromagnética incidente..$^{20,23,24}$ Quando a nanopartícula não se enquadra dentro das condições estabelecidas pela teoria de Mie, como aquelas relacionadas com o tamanho, outros fatores se tornam relevantes, os quais levam as explicações das diferenças observadas nos espectros de extinção, como visto na Figura 2, em que há uma dependência do espectro com o tamanho da nanopartícula.

Quanto maior a nanopartícula, maior o desvio da aproximação de Mie, pois fornece dados que não corroboram com os verificados experimentalmente, uma vez que o campo elétrico da onda incidente gera induções eletromagnéticas não uniformes sobre a partícula. Estas induções não homogêneas ocasionam modos de excitação e relaxação diferentes para os elétrons contidos na partícula. . $23,27,30^{O}$ aumento da dimensão gera deslocamentos da frequência de excitação plasmônica para energias menores (redshifts). Estes deslocamentos ocorrem devido à maior densidade de cargas nas nanopartículas, proporcionando ao sistema uma maior inércia oscilatória, modificando a frequência natural de oscilação para menores energias. O alargamento da banda de absorção plasmônica, ocorre uma vez que a densidade eletrônica não oscila em fase (homogeneamente), ocasionando que diferentes densidades eletrônicas sejam excitadas em diferentes frequências ${ }^{23,27,30}$ Para o aumento das dimensões, a função dielétrica da nanopartícula terá um comportamento relacionado com a função dielétrica do material como bulk. Ao aglomerarem-se para formação de clusters, ou nanopartículas com algumas dezenas ou mais de nanômetros, os orbitais eletrônicos dos átomos formadores das estruturas sobrepõem-se, formando bandas de energia, como na formação de orbitais moleculares. Em materiais condutores como os metais, estas bandas se estruturam de tal forma que a banda de valência (BV) é totalmente preenchida e permeia a banda de condução (BC). A BC é semipreenchida, ou seja, os elétrons não preenchem todos os níveis 

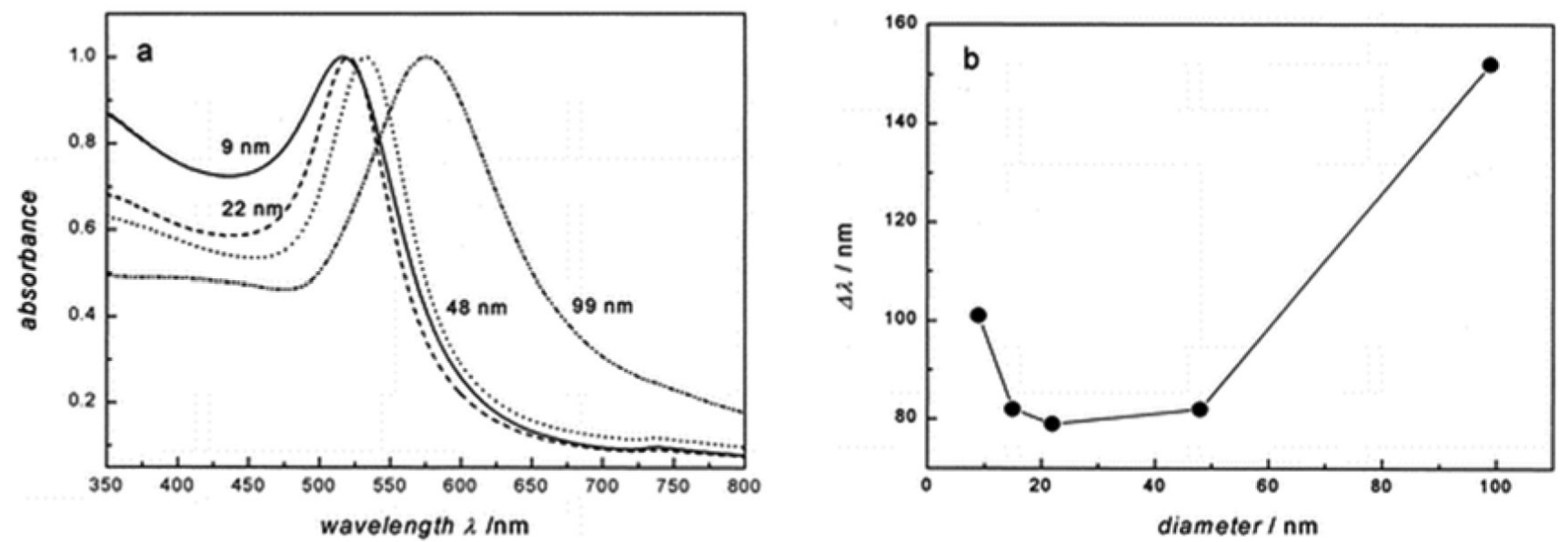

Figura 2. (a) Espectro de absorção UV-Vis de nanopartículas de ouro de diferentes tamanhos em água. Os espectros de absorção foram normalizados para seus máximos, sendo em ordem do tamanho 517, 521, 533 e $575 \mathrm{~nm}$, respectivamente. (b) Largura à meia altura da banda plasmônica em função do diâmetro da nanopartícula. Extraído da ref. 27 com permissão da American Chemical Society

possíveis no interior da banda. Nessa situação, a função dielétrica da NP-M é dada pelo modelo de Drude-Lorentz conforme descrito na Equação 7.

$$
\varepsilon(\omega)=\varepsilon_{\text {inter }}(\omega)+\varepsilon_{\text {intra }}(\omega)
$$

A contribuição da função dielétrica referente aos elétrons que absorvem energia para transições entre as bandas de energias, ou seja, transições interbandas $\left(\varepsilon_{\text {inter }}\right)$, são proporcionadas pela absorção de energia de elétrons que realizam saltos quânticos, de estados ocupados para estados vazios entre as bandas de energia separadas por um nível energético (gap). Para a maioria dos metais, estes saltos quânticos ocorrem com energia na região do ultravioleta. Estas transições interbandas não contribuem para o fenômeno da ressonância plasmônica. A função dielétrica relacionada com as transições intrabanda $\left(\varepsilon_{\text {intra }}\right)$ estão associadas com os elétrons em bandas semipreenchidas, que transitam na região da energia de Fermi, migrando de sítios preenchidos para sítios vazios. Estas transições também são verificadas entre bandas totalmente preenchidas que se sobrepõem em bandas semipreenchidas.

Os fenômenos envolvidos nas transições intrabanda dos elétrons se dão através da absorção de energia, entretanto, as energias envolvidas são menores se comparadas as transições interbandas. As energias relacionadas às transições intrabanda para metais são da ordem de poucos $\mathrm{eV}$, devido à pouca energia necessária para os elétrons movimentarem-se. A utilização desta formulação para a função dielétrica da NP-M é a primeira consideração a ser feita para contribuições relativas ao efeito de tamanho da NP e excitação plasmônica, de modo que a função dielétrica para os elétrons livres (elétrons que não possuem sítios preferenciais) é dada pela Equação 8. ${ }^{31}$

$$
\varepsilon(\omega)=1-\frac{\omega_{p}^{2}}{\omega^{2}+i \gamma \omega}
$$

em que $\omega_{p}$, dado pela equação $\omega_{p}=\sqrt{\frac{\pi N e^{2}}{m}}$, representa a frequência de oscilação de plasmon para os elétrons livres, sendo $\mathrm{N}$ o número de elétrons, m a massa efetiva dos elétrons e $\gamma$ é um parâmetro associado à relaxação do sistema, sendo dado por:

$$
\gamma(r)=\gamma_{0}+\mathrm{A} \frac{\mathrm{V}_{\mathrm{F}}}{\mathrm{r}}
$$

em que $\gamma_{0}$ trata-se das contribuições de relaxamento para a frequência de vibração dos elétrons, dada as colisões elétrons - elétrons, elétrons - fônons, elétrons - limite físico superficial, para as contribuições de bulk. A outra parcela da equação, definida no trabalho de Pinchuk et al. ${ }^{32}$ recondiciona o fator de relaxamento (damping) relacionando parâmetros importantes para sistemas menores que o livre caminho médio. $\mathrm{O}$ termo $\mathrm{V}_{\mathrm{F}} / \mathrm{r}$ relaciona a velocidade de Fermi dos elétrons $\left(\mathrm{V}_{\mathrm{F}}\right)$ com o raio (r) da nanopartícula. $\mathrm{O}$ parâmetro $\mathrm{A}$ consiste em duas contribuições aditivas, ${ }^{33}$ dadas por $\mathrm{A}=\mathrm{A}_{\text {tamanho }}+\mathrm{A}_{\text {interface }}$. Este parâmetro agrega fatores de amortecimento dependentes do tamanho (damping size) e do meio em que a NP-M está hospedada. No trabalho de Persson ${ }^{34}$ o parâmetro $\mathrm{A}_{\text {interface }}$ é dado como chemical interface damping (CID), referindo-se a estados energéticos vazios das moléculas que circundam as nanopartículas. A banda formada por estes níveis energéticos se acopla com os estados da banda de condução da nanopartícula condutora (metálica), formando novos estados possíveis de relaxamento para o sistema nanopartícula meio circundante. Estes mecanismos de relaxação são considerações de bastante relevância nas explicações relacionadas com os espectros de extinção de nanopartículas (Figura 2). Nas nanopartículas com tamanho menores que dezenas de nanômetros são evidenciados os deslocamentos da banda de absorção plasmônica para energias maiores (blue-shifts).

\section{Teoria de Maxwell-Garnett}

James Clerk Maxwell e William Garnett desenvolveram em 1904 uma teoria satisfatória para explicar sistemas que não se enquadram dentro dos parâmetros de diluição das nanopartículas na matriz, como as adotadas na Teoria de Mie (condições de sítio individualizado excitado - nanopartícula isolada), ou seja, sistemas em que há interação entre os campos eletromagnéticos plasmônicos de nanopartículas vizinhas. Em sistemas com a distância entre as partículas da ordem de $\mathrm{d}<5 \mathrm{R}$, sendo $\mathrm{R}$ o raio das nanopartículas e $\mathrm{d}$ a distância centro a centro das nanopartículas vizinhas, são observados efeitos de alargamento e deslocamento da banda de ressonância plasmônica para menores energias (red-shift) nos espectros de extinção. ${ }^{35,36}$ Ainda, pode-se observar o aparecimento de ombros (mais de um pico de absorção característico) em casos relacionados com o aglomeração de nanopartículas formando geometrias de bastonetes, elipsoides, entre outros.

A teoria de Maxwell-Garnett trata-se de uma teoria de meio efeti$v^{37-39}$ entre outras existentes. Nesta teoria, determina-se um fator de ajuste a ser considerado para todo o sistema (fator de preenchimento, 
f), utilizando-se uma média estatística do $\mathrm{V}_{\text {Cluster }}$, que consiste no volume dos agregados constituintes da matriz dielétrica onde estão dispersos (não absorvedor e homogêneo) e pelo $\mathrm{V}_{\text {geom cluster, }}$ que consiste no volume individual de uma partícula com geometria arbitrária (cilíndricas, esféricas, quadráticas) que compõe os agregados na matriz, dado pela seguinte expressão:

$$
f=\frac{V_{\text {Cluster }}}{V_{\text {geomcluster }}}
$$

Se considerarmos o volume dos agregados como esféricos, podemos reescrever a expressão anterior da seguinte forma:

$$
f=\frac{N R^{3}}{r^{3}}
$$

em que r é o raio do volume esférico de uma partícula do agregado, $\mathrm{R}$ é o raio da partícula-agregado e $\mathrm{N}$ é o número de partículas-agregado.

Assumindo que a teoria de Lorentz sobre o campo elétrico agindo sobre um único átomo (carga isolada) possa ser estendida para o sistema partícula-agregado como um todo, permitindo calcular a polarização para as propriedades dielétricas, ${ }^{23,37,40}$ podemos encontrar o campo elétrico efetivo localizado numa dada partícula-agregado conforme a Equação 12.

$$
E_{\text {local }}=E_{\lambda}+E_{p a}+E_{d}+E_{\text {prox }}
$$

em que $E_{\lambda}$ é o campo proveniente da onda eletromagnética incidente, $E_{p a}$ é o campo dado pelas cargas externas à superfície da partícula-agregado, $E_{d}$ é o campo com origem na formação do dipolo na superfície externa e $E_{\text {prox }}$ é associado com as polarizações no interior da partícula-agregado. A Equação 12 pode ser reescrita da seguinte forma:

$$
E_{\text {local }}=E_{\text {Maxwell }}+E_{d}+E_{\text {prox }}
$$

em que $E_{\text {Maxwell }}$ é o somatório do campo da onda incidente e do campo gerado pela polarização das cargas na superfície externa do sistema representado na Figura 3. O meio onde se encontra o sistema partícula-agregado é considerado um meio real não absorvedor $\varepsilon_{m}$.

Quando o fator de preenchimento $f$ está abaixo de $10^{-3}$, é possível considerar que sistemas partículas-agregado vizinhos não interfiram uns com os outros. ${ }^{23}$ Sob estas parametrizações $E_{\text {prox }}=0$, uma vez que no sistema esférico proposto por Lorentz, interações destrutivas entre os campos no interior do sistema cancelam-se mutuamente no

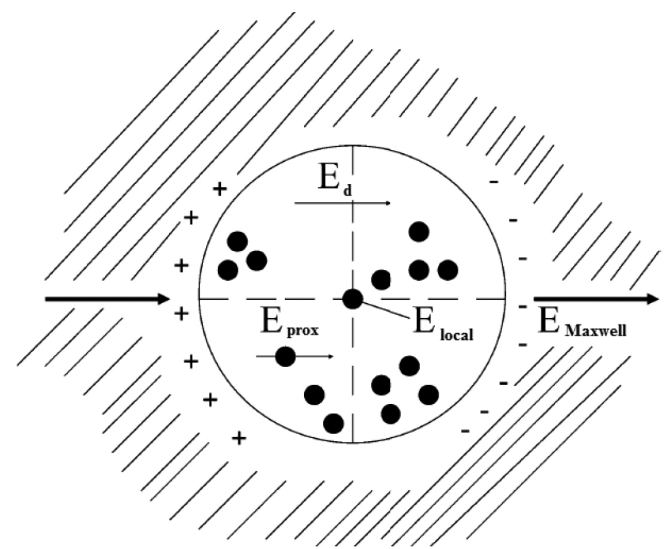

Figura 3. Representação do campo elétrico presente em um sistema nanopartícula-agregado. Adaptada da ref. 23 com permissão da American Chemical Society centro, sendo levado em conta para o campo local somente $E_{d}$ e $R_{\text {Maxwell }}$ (o valor médio para o campo elétrico de Maxwell está representado simplesmente por E), que estão descritos abaixo:

$$
\begin{gathered}
E_{d}=\int_{0}^{\pi}\left(\frac{P \cos \theta}{R^{2}}\right) \cos \theta\left(2 R^{2} \sin \theta\right) d \theta=\frac{4 \pi}{3} P \\
E_{\text {Local }}=E+\frac{4 \pi}{3} P
\end{gathered}
$$

sendo $\theta$ o ângulo de polarização das partículas-agregado. A relação entre a polarização $(\mathrm{P})$ e o campo elétrico $(\mathrm{E})$ nos fornece a suscetibilidade com que a partícula-agregado se polariza na presença de um campo elétrico externo ( $\chi$ (Equação 15$)$. A polarização, assim como o momento de dipolo na partícula-agregado, podem ser obtidos através do $\mathrm{E}_{\mathrm{Local}}$. $\mathrm{O}$ momento de dipolo $(\mu)$ e a polarização $(\mathrm{P})$ são dados nas Equações 16 e 17.

$$
\begin{gathered}
\chi=\frac{P}{E}=\frac{\sum_{i} N_{i} \alpha_{i}}{1-\frac{4 \pi}{3} \sum_{i} N_{i} \alpha_{i}} \\
\mu=\alpha E_{\text {Local }} \\
P=\sum_{i} N_{i} \mu_{i}=\sum_{i} N_{i} \alpha_{i} E_{\text {Local }}(i)
\end{gathered}
$$

sendo $N_{i}$ a densidade, e $\alpha_{\mathrm{i}}$ a polarizabilidade por unidade de (i) partícula-agregado. Substituindo a Equação 14 na 17 teremos:

$$
P=\sum_{i} N_{i} \mu_{i}=\sum_{i} N_{i} \alpha_{i}\left(E+\frac{4 \pi}{3} P\right)
$$

A polarizabilidade para uma esfera com raio $r$ e permissividade elétrica $(\epsilon)$ num meio real com permissividade $\epsilon_{m}$ é calculada mediante a relação de Clausius Massotti, ${ }^{23}$ dada por:

$$
\alpha=\frac{\epsilon-\epsilon_{m}}{\epsilon+2 \epsilon_{m}} R^{3}
$$

Pode-se considerar que a permissividade elétrica do sistema partícula-agregado seja homogênea como um todo em sistemas que as parametrizações para regime quase estático sejam viáveis dentro da teoria de meio efetivo, de modo que possa ser substituída por uma função dielétrica efetiva $\left(\varepsilon_{\text {efe }}\right)$, descrita como $\varepsilon_{\text {efe }}=\varepsilon_{\text {efe real }}+i \varepsilon_{\text {efe imaginária }}$. A função dielétrica complexa permite que, mesmo para um meio não homogêneo, a resposta a um campo elétrico externo seja obtida como uma média estatística linear para todo o volume. ${ }^{27,39}$ A relação entre a polarizabilidade com a função dielétrica efetiva da partículaagregado é dada pela Equação 20:

$$
\propto_{e f e}=\frac{\varepsilon_{e f e}-\varepsilon_{m}}{\varepsilon_{e f e}+2 \varepsilon_{m}}=\frac{4 \pi}{3} \sum_{i} N_{i} R^{3} \frac{\varepsilon-\varepsilon_{m}}{\varepsilon+2 \varepsilon_{m}}
$$

Substituindo a densidade volumétrica (geometria esférica) pelo fator de preenchimento do sistema, temos a relação de Maxwell-Garnett:

$$
\frac{\varepsilon_{e f e}-\epsilon_{m}}{\varepsilon_{e f e}+2 \epsilon_{m}}=f \frac{\varepsilon-\varepsilon_{m}}{\varepsilon+2 \varepsilon_{m}}
$$

De acordo com a relação de Maxwell-Garnett, o aumento da função $\varepsilon_{\text {efe }}$ faz com que a polarizabilidade do sistema aumente, resultando em uma maior separação de cargas nas partículas-agregado 

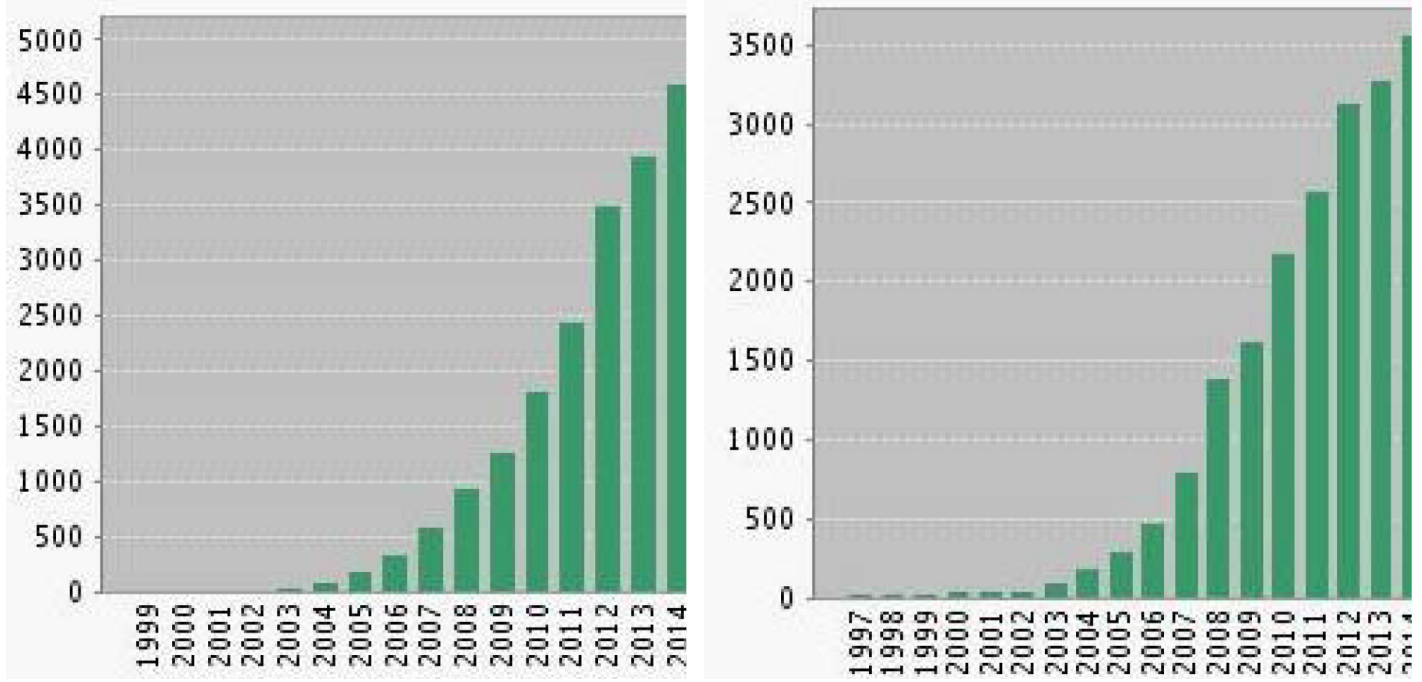

Figura 4. Publicações disponíveis na "Web of Science" (em janeiro de 2016) associadas às palavraschave (a) "localized surface plasmon resonance" "e "sensor" $e$ (b) "localized surface plasmon resonance" e "biosensor"

e, por consequência, uma força de restauração menor. Este comportamento se reflete no efeito LSPR que passa a ocorrer com menores valores energéticos, afetando diretamente a aplicação destes materiais em sensores, pois de acordo com Jain et al., ${ }^{41}$ menores valores de frequência plasmônica indicam maior sensibilidade devido a maior facilidade de polarização dos elétrons.

\section{APLICAÇÃO DE NANOPARTÍCULAS PLASMÔNICAS EM SENSORES BIOLÓGICOS}

A aplicação do efeito plasmônico em biossensores foi primeiramente demonstrado em 1982 por Nylander e Liedberg através da obtenção de um sensor para gás. ${ }^{42-45}$ No entanto, foi no início dos anos 90 que o primeiro biossensor plasmônico foi lançado no mercado, sendo este um biossensor de bancada. Desde então, uma grande variedade de métodos para detecção de marcadores biológicos envolvendo processos cinéticos como adsorção-dessorção, interações proteína-ligante, interações antígeno-anticorpo, receptor ligante e proteína-DNA/RNA, vem sendo desenvolvidos. ${ }^{46-55}$ As principais vantagens destes sensores plasmônicos se concentram em elevadas sensibilidades e medidas em tempo real sem a necessidade de marcação de biomoléculas.

Atualmente, pesquisadores buscam obter biossensores miniaturizados com alta sensibilidade e baixo limite de detecção (LOD, do inglês Limit of Detection). Neste intuito, tem se explorado o fenômeno LSPR através da fabricação de diferentes nanoestruturas metálicas. ${ }^{54,55-60}$ A miniaturização dos biossensores LSPR é possível por possibilitar que os substratos plasmônicos sejam integrados com sistemas microfluídicos e sistemas ópticos simples. ${ }^{61}$ Neste sistema integrado, a superfície plasmônica pode ser modificada possibilitando a presença de vários pontos de detecção seletiva, além de permitir a construção de curvas de calibração in situ. ${ }^{55}$ Como resultado, o número de publicações relacionadas ao efeito LSPR torna-se cada vez mais significativo ao longo dos anos (Figura 4), cabendo destacar que há 13 anos $80 \%$ destas publicações em LSPR já estavam relacionadas a aplicação em biossensores ${ }^{52}$ devido à necessidade dos estudos relacionados a sensibilidade e interações biomoleculares. ${ }^{48,62}$

Conforme descrito na seção "Aspectos teóricos sobre o LSPR", o efeito LSPR ocorre em nanoestruturas metálicas com dimensões muito menores que o comprimento de onda da luz incidente. Nesta situação ocorre a separação momentânea das cargas, conforme ilustrado na Figura 5, em que a intensidade da onda evanescente resultante da propagação plasmônica decresce exponencialmente do vermelho para o azul. Da mesma forma que o SPR, o LSPR é afetado pela constante dielétrica do meio $(\varepsilon)$ e, portanto, pelo índice de refração (n), uma vez que estão relacionados pela expressão $\varepsilon=n^{2} A$ adsorção de moléculas sobre a superfície destas nanoestruturas resulta em mudanças no índice de refração próximo à superfície do metal e como consequência a LSPR ocorrerá em uma frequência diferente. Esta alteração de frequência de ressonância plasmônica é explorada no desenvolvimento destes biossensores. ${ }^{49,62-64}$

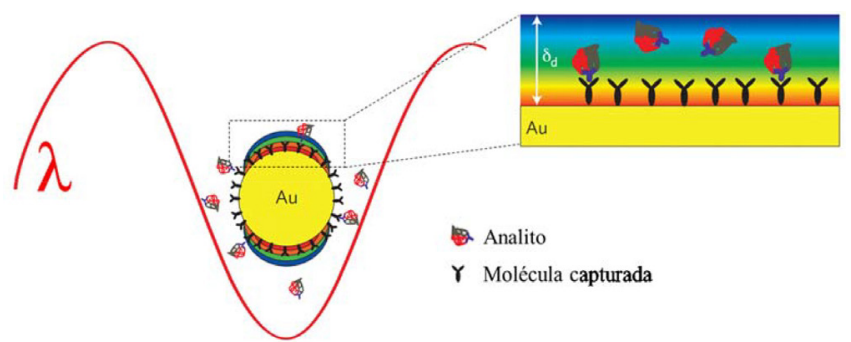

Figura 5. Representação esquemática do efeito LSPR em uma nanopartícula de ouro isolada e modificada para bioreconhecimento do analito. Em detalhe: Desenho ilustrativo do gradiente da onda plasmônica evanescente que decresce exponencialmente do vermelho para o azul. Extraído da ref. $62 \mathrm{com}$ permissão da Macmillan Publishers Ltd.

Para que o metal transdutor possua especificidade e/ou seletividade, utiliza-se agentes de bioreconhecimento que podem possuir um ou mais sítios ativos para ligações e imobilizações de moléculas alvo. A imobilização destes agentes pode ocorrer diretamente na superfície metálica ou através de modificações químicas da superfície; nesta etapa é importante que a superfície do metal transdutor possibilite e facilite a interação de um número suficiente de elementos de bioreconhecimento com os analitos, evitando ligações não específicas, ou seja, falsos positivos. Existem diferentes modos de detecção que podem ser empregados dependendo do analito a ser detectado, devendo ser considerados o tamanho e a concentração do analito, além das características da sua ligação com o elemento de bioreconhecimento, por exemplo: detecção direta; por configuração sanduíche, por competição; por inibição e por detecção indireta ${ }^{65}$ Estes modos de detecção podem ser empregados na detecção de DNA, proteínas, anticorpos e outras biomoléculas de interesse. 


\section{Avaliação do desempenho de biossensores plasmônicos}

Diferentes tipos de biossensores plasmônicos têm sido desenvolvidos nos últimos anos. ${ }^{63-72}$ Uma das propriedades mais utilizadas para comparar os sensores é a sensibilidade bulk $\left(S_{b}\right)$. O valor de $S_{b}$ é obtido experimentalmente monitorando a banda plasmônica ao expor a superfície nanoestruturada a soluções com diferentes índices de refração. É expresso em nm por unidade de índice de refração $\left(\mathrm{nm} \mathrm{RIU}{ }^{-1}\right)$ e matematicamente pode ser representado através da Equação 22, dada pela razão entre a variação no comprimento de onda da banda plasmônica $\left(\Delta \lambda_{\max }\right)$ e a variação no índice de refração $(\Delta n):^{49,64-66,73}$

$$
S_{b}=\frac{\Delta \lambda_{\max }}{\Delta n}
$$

A sensibilidade de superfície (sensibilidade à adsorção de moléculas) leva em consideração propriedades intrínsecas do material (como o valor do campo eletromagnético da NP-M, $l_{d}$ ) e variáveis controláveis (como concentração e tamanho molecular do analito). Estes fatores aparecem nas expressões relacionadas à mudança do índice de refração e ao deslocamento do comprimento de onda do máximo de extinção (Equações 23 e 24). A mudança no índice de refração causada pela imobilização de moléculas na superfície de nanoestruturas metálicas depende não somente da concentração do analito, mas também de suas propriedades estruturais. Quando a imobilização ocorrer imediatamente sobre a superfície, a resposta do biossensor estará associada à variação do índice de refração local $(\Delta n)$, expresso pela Equação $23::^{74}$

$$
\Delta n=\left(\frac{d n}{d c}\right) \frac{\Gamma}{h}
$$

em que $\left(\frac{d n}{d c}\right)$ é o aumento do índice de refração com aumento da concentração do analito, $\Gamma$ é a concentração da superfície em massa/área e $h$ é a altura da camada molecular formada na superfície. Observe que $h$ é inversamente proporcional a $\Delta n$, devido ao caráter evanescente da banda plasmônica, que se torna menos intensa à medida que $h$ aumenta; nesta situação, a propagação plasmônica perde a sensibilidade às mudanças no índice de refração.

A variação no deslocamento do comprimento de onda do máximo de extinção $\left(\Delta \lambda_{\max }\right)$, causado pela variação no índice de refração $(\Delta n)$, como consequência da adsorção molecular na superfície da NP-M, depende do decaimento característico do campo eletromagnético das nanopartículas metálicas $\left(l_{\mathrm{d}}\right)$ e pode ser expressa pela Equação $24:^{62,65,69}$

$$
\Delta \lambda_{\max }=S_{b} \Delta n\left[1-e^{\left(\frac{-2 h}{l_{d}}\right)}\right]
$$

Apesar da $S_{b}$ ser extensivamente utilizada na caracterização de biossensores plasmônicos, seu valor não leva em consideração a homogeneidade da nanoestrutura, que é refletida diretamente na banda do espectro de extinção. No entanto, pode-se representar a sensibilidade através da Figura de Mérito (FOM, do inglês Figure of Merit) expressa em $\mathrm{RIU}^{-1}$, que representa a razão entre $S_{b}$ e a largura à meia altura da banda plasmônica (FWHM, do inglês Full Width at Half Maximum), conforme representado na Equação 25:49,69,73,79

$$
F O M=\frac{S_{b}}{F W H M}
$$

Recentemente, o conceito de FOM foi expandido quando Bahrami et al. ${ }^{73}$ consideraram características físicas da plataforma utilizada em um biossensor para estimar valores de FOM. Como consequência, a comparação de diferentes plataformas usando a FOM é um dos métodos mais utilizados, considerando propriedades atômicas intrínsecas do metal bem como a forma do material plasmônico usada na detecção das biomoléculas.

A resolução (Res) expressa a menor variação no índice de refração mensurável para o dispositivo, e se torna uma ferramenta complementar da FOM por considerar o ruído na medida experimental. A Equação 26 mostra a relação entre o ruído $\sigma$ (normalmente 3 vezes a média do desvio padrão do sinal) e $S_{b}$ no cálculo da Res:

$$
\operatorname{Res}=\frac{\sigma}{S_{b}}
$$

O LOD é também muito utilizado na comparação de diferentes plataformas e nos informa a quantidade mínima detectável do analito. Ele é geralmente expresso como sendo o valor médio do branco (amostra sem o analito) mais três vezes seu desvio padrão. Em complementação ao LOD, o Limite de Quantificação (LOQ) expressa o limite de concentração a partir da qual pode-se quantificar o analito; esta propriedade é geralmente expressa em termos do valor médio do branco mais cinco vezes seu desvio padrão.

\begin{tabular}{|c|c|c|c|}
\hline Nanoestrutura plasmônica & Faixa de detecção & Analito & Ref. \\
\hline Arranjo hexagonal de NPAu triangulares & $0,3 \mathrm{~nm}\left(\mathrm{pg} \mathrm{ml}^{-1}\right)^{-1}$ & proteína p53 & 75 \\
\hline NPCu depositadas sobre nanopartículas de sílica & $10 \mathrm{fmol} \mathrm{L}^{-1}$ & DNA & 102 \\
\hline Arranjo hexagonal de NPAu esféricas & $\left.0,4 \mathrm{~nm}(\mathrm{ng} \mathrm{mL})^{-1}\right)^{-1}$ & anticorpo PSA & 76 \\
\hline Nanobastões de ouro & $94 \mathrm{pmol} \mathrm{L}^{-1}$ & estreptavidina & 97 \\
\hline NPAu & $0,1 \mathrm{ng} \mu \mathrm{L}^{-1}$ & Brettanomyces bruxellensis & 103 \\
\hline NPAu & $1,40 \mathrm{ng} \mathrm{mL}^{-1}$ & pesticidas organofosforados & 105 \\
\hline Cogumelos de ouro & $200 \mathrm{pmol} \mathrm{L}^{-1}$ & citocromo C & 77 \\
\hline Cogumelos de ouro & $15 \mathrm{ng} \mathrm{mL}^{-1}$ & alfa-fetoproteína & 77 \\
\hline NPAu & $0,1 \mathrm{fg} \mathrm{mL}^{-1}$ & biomarcadores de câncer & 107 \\
\hline NPAu imobilizadas em fibra óptica & $\mathrm{ppb}$ & TNT (através de cisteamina) & 106 \\
\hline
\end{tabular}

A Tabela 1 exemplifica a aplicação de diferentes nanoestruturas plasmônicas na detecção de biomoléculas e seus desempenhos estão descritos em termos do LOD.

Tabela 1. Exemplos de nanoestruturas plasmônicas aplicadas na detecção direta e indireta de biomoléculas 
A forma de propagação do LSPR nestas nanoestruturas pode ser explorada para melhorar o desempenho do biossensor, por exemplo, com o objetivo de melhorar a sensibilidade. Ferreira et al. ${ }^{59}$ estudaram o desempenho de biossensores utilizando arranjos de nanoburacos perfurados em filmes de ouro com $100 \mathrm{~nm}$ de espessura. Neste trabalho observaram uma melhora na sensibilidade que permitiu a detecção de proteínas em quantidades attomolares. Para este fim a ressonância plasmônica foi confinada dentro dos orifícios através do recobrimento do filme de ouro com uma camada de $\mathrm{SiO}_{\mathrm{x}}$. Em outro trabalho, Dmitriev et al. ${ }^{78}$ demonstram através de resultados teóricos e experimentais (Figura 6) uma estratégia para aumentar o efeito do campo eletromagnético durante a propagação do plasmon em nanodiscos de ouro baseado na interação nanodisco-substrato. Visando demonstrar o efeito da distribuição espacial do campo gerado durante o efeito LSPR na sensibilidade bulk, a Figura 6 compara a distribuição do campo para um nanodisco de ouro diretamente depositado no substrato de $\mathrm{SiO}_{2}$ e suportado por um pilar de dielétrico (Figuras $6 \mathrm{~b}$ e c, respectivamente). É possível observar que o aumento da distância entre o substrato e o material plasmônico reduz a sobreposição entre o campo local (induzido e o substrato), intensificando o campo eletromagnético resultante da ressonância plasmônica e, portanto, aumentando a sensibilidade bulk das nanoestruturas em que o nanodisco não foi depositado diretamente no substrato (Figura 6a, $750 \mathrm{~nm}$ ). O aumento de sensibilidade com a distância do substrato depende do comprimento de onda analisado, sendo o máximo de sensibilidade obtida para distâncias de cerca de $50 \mathrm{~nm}$ e $80 \mathrm{~nm}$ para os comprimentos de onda 600 e $650 \mathrm{~nm}$, respectivamente.

\section{Comparação do desempenho de biossensores plasmônicos utilizando nanopartículas}

A oscilação do campo eletromagnético sobre a superfície de nanopartículas metálicas devido à incidência de luz na região do visível é fortemente dependente da forma e tamanho da estrutura. ${ }^{69,73,74,79-82}$ Por exemplo, nanoesferas são facilmente obtidas e se caracterizam por uma distribuição da polarizabilidade na superfície concentrada nos polos. Por outro lado, através de sínteses com procedimentos um pouco mais elaborados, pode-se obter estruturas mais complexas como nanobipirâmides, nanobastões, nanoshells, nanobranches, etc. cujas estruturas resultam na concentração do campo eletromagnético em regiões diferentes da nanoestrutura, alterando as propriedades ópticas do nanomaterial. A relação da estrutura com a concentração do campo eletromagnético foi estudada tanto experimentalmente quanto através de trabalhos teóricos. Como consequência dos diferentes tamanhos e formatos, a interação do campo eletromagnético proveniente da luz visível ocorre longitudinalmente e transversalmente ao longo da nanoestrutura plasmônica, resultando em diferentes espectros de extinção. ${ }^{83-93}$ Esta alteração do modo de propagação do LSPR permite a obtenção de biossensores plasmônicos com diferentes desempenhos, conforme resumido na Tabela 2, através da comparação dos valores de $S_{b}$ e $F O M$, sendo os mais promissores aqueles que apresentam valores mais elevados.

Além dos valores de $S_{b}$ e $F O M$, deve-se avaliar o custo da síntese ou fabricação das nanoestruturas, sua reprodutibilidade e sensibilidade à adsorção de moléculas à superfície. A literatura descreve inúmeros biossensores LSPR utilizando nanopartículas. Por exemplo, Kim et al. ${ }^{102}$ desenvolveram um biossensor LSPR usando um arranjo de nanopartículas de cobre sobre nanopartículas de sílica para imobilização de moléculas alvo de DNA, alcançando um LOD de $10 \mathrm{fmol} \mathrm{L}{ }^{-1}$. Marinakos et al..$^{97}$ utilizaram nanobastões de ouro quimisorvidos em vidro para detecção de estreptavidina devido à sua alta afinidade às moléculas de biotina, conseguindo um LOD de 94 pmol L-1. Recentemente, Manzano et al. ${ }^{103}$ obtiveram NPAu através da evaporação térmica para detecção indireta de Brettanomyces bruxellensis, micro-organismo presente no vinho. O biossensor se mostrou promissor para detecção de baixas quantidades de micro-organismos patogênicos em comida e amostras de bebida, atingindo um LOD de alvo de $0,1 \mathrm{ng} \mu \mathrm{L}^{-1}$. Na mesma linha, Zang et al. ${ }^{104}$ desenvolveram um biossensor para detecção de IgG de rato utilizando um compósito de nanocubos (NCs) de prata com quitosana adsorvidos sobre um filme de ouro modificado com ácido 3-mercaptopropiônico (MPA). Essa plataforma mostrou uma diminuição de cerca de quatro vezes no limite de quantificação em comparação ao biossensor tradicional, obtido apenas com o filme de ouro modificado com MPA. NPAu foram usadas por Li et al. ${ }^{105}$ para detecção de pesticidas organofosforados. O sensor demonstrou resposta linear entre $0,02-1,42 \mu \mathrm{g} \mathrm{mL} \mathrm{m}^{-1}$ e LOD de $1,40 \mathrm{ng} \mathrm{mL}{ }^{1}$ para a detecção de metamidofós.

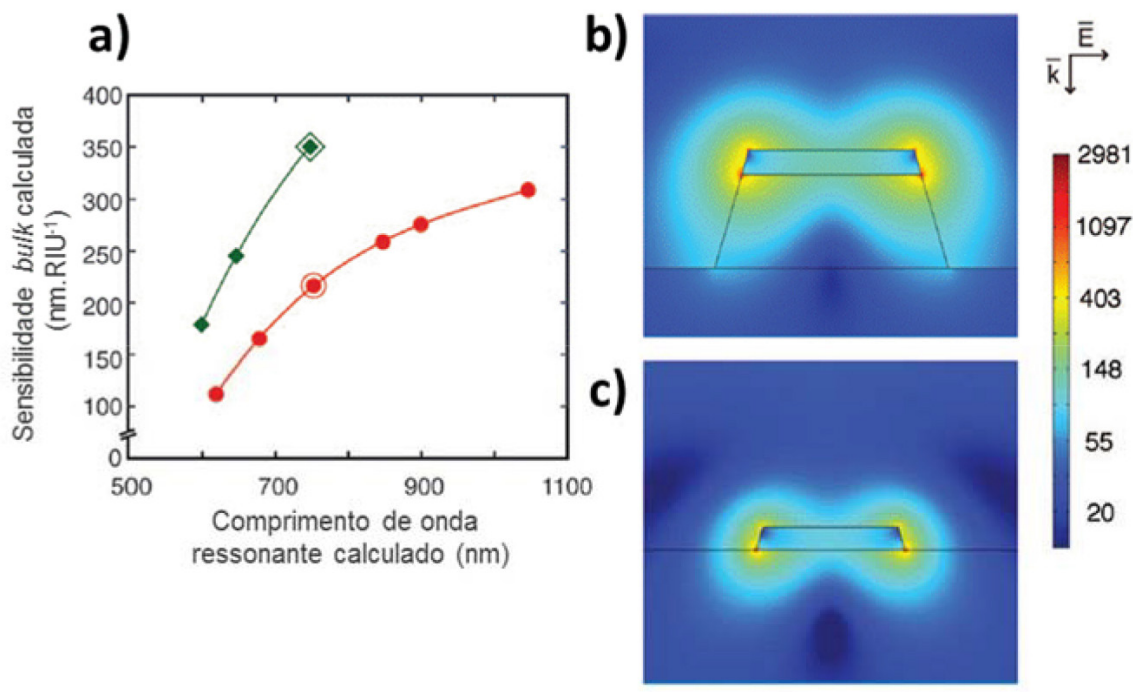

Figura 6. (a) Sensibilidade a mudanças no índice de refração em função do comprimento de onda plasmônico para o nanodisco de ouro colocado diretamente sobre o substrato de $\mathrm{SiO}_{2}$ (vermelho) e sobre um pilar a uma distância de $80 \mathrm{~nm}$ do $\mathrm{SiO}_{2}$ (verde). Simulação teórica obtida por "finite-element electrodynamics" para a distribuição do campo elétrico (amplitude total do campo E) dos pontos marcados ( $750 \mathrm{~nm}$ ) para (b) os nanodiscos suportados pelo pilar e (c) para o nanodisco colocado diretamente sobre o substrato. O campo E está plotado em escala logarítmica para melhorar a visibilidade. Adaptado da ref. 78 com permissão da American Chemical Society 
Tabela 2. Valores de $S_{b}$ e FOM para diferentes nanoestruturas plasmônicas. Informações extraídas das referências indicadas com permissão da Sociedade Brasileira de Química e da American Chemical Society

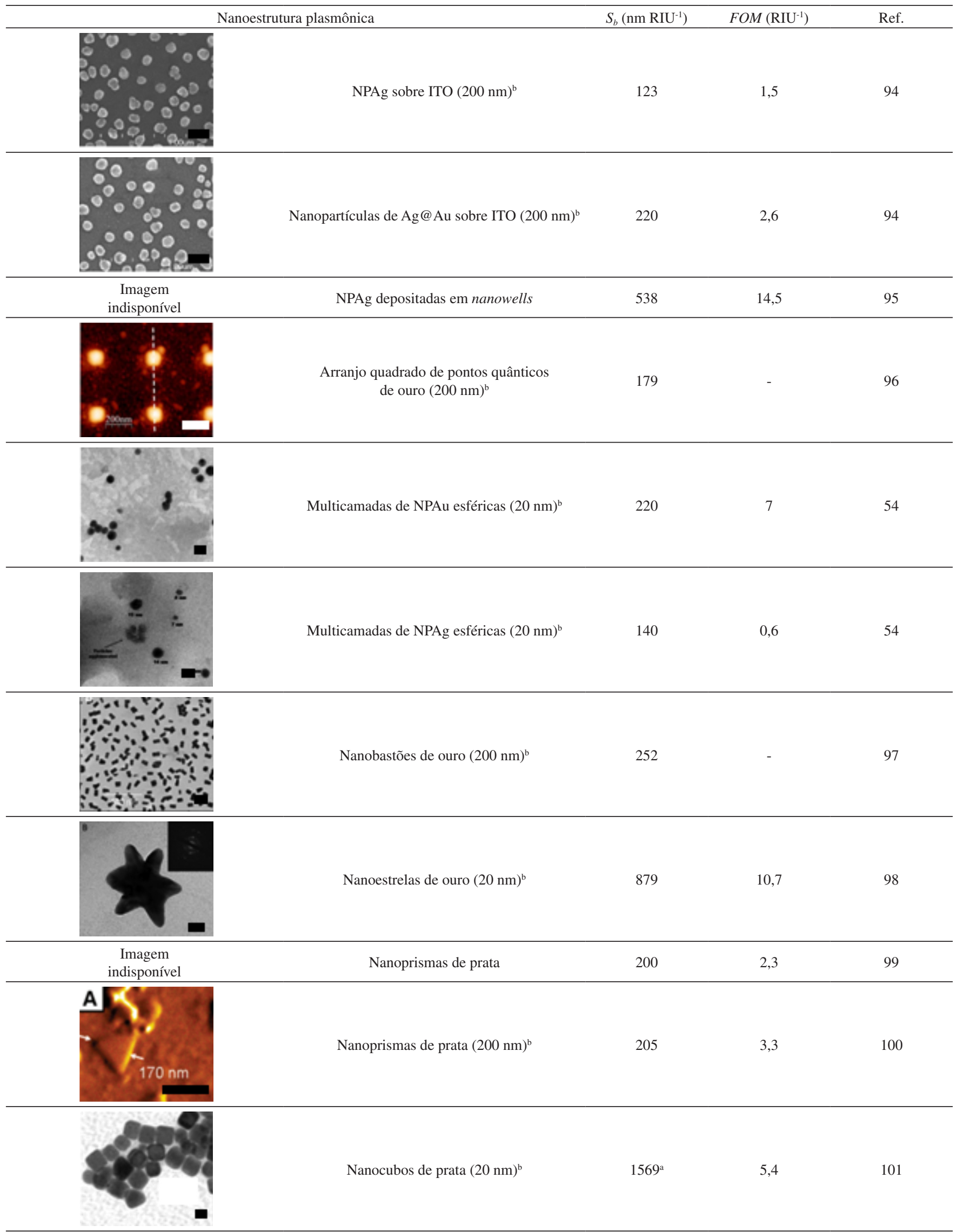


A integração de NPs-M com fibras ópticas podem também resultar em biossensores interessantes, como no trabalho de Bharadwaj et al. ${ }^{106}$ no qual foi desenvolvido um biosensor a base de NPAu imobilizadas em fibra óptica com formato em U. As NPAu foram previamente funcionalizadas com cisteamina, L-cisteamina e ácido 4-mercaptobenzóico que funcionam como sítios de ligação para a detecção de vapores explosivos (2,4,6-trinitrotolueno (TNT); 2,4-dinitrotolueno (DNT); ciclotrimetilenotrinitramina (RDX) e tetranitrato de pentaeritritol (PETN)). A detecção de vapores de TNT atingiu um LOD na ordem de ppb.

Nanoestruturas metálicas podem ser utilizadas não apenas como substrato, mas também como marcadores das moléculas alvo. Kosaka e colaborabores ${ }^{107}$ conseguiram combinar propriedades optoplasmônicas e mecânicas em um transdutor LSPR para a detecção de marcadores de câncer. Nesse trabalho o biomarcador é primeiramente reconhecido por um anticorpo ancorado à superfície e, em seguida, um segundo anticorpo em solução identifica a região livre do biomarcador ancorado. NPAu são presas neste segundo anticorpo atuando como um marcador plasmônico e de massa. Essas duas formas de interações são detectadas através de um cantilever de silício que faz a detecção em termos da alteração de massa, atuando também como uma cavidade óptica que amplia o sinal plasmônico das nanopartículas. Com isso, atingiu-se um LOD de $1 \times 10^{16} \mathrm{~g} \mathrm{~mL}^{-1}$.

\section{APLICAÇÃO DE MATERIAIS PLASMÔNICOS EM CÉLULAS SOLARES}

A utilização de materiais plasmônicos em células solares possibilita a redução da espessura física da camada fotoativa, ao mesmo tempo que aumenta a capacidade do material em absorver luz. ${ }^{108}$ Dois mecanismos principais são geralmente considerados para entender este processo: o primeiro baseia-se na incorporação de nanopartículas metálicas no dispositivo para que aprisione a luz através do aumento no percurso óptico dentro da célula; no segundo as NPs-M funcionam como "antenas" que amplificam o campo elétrico próximo a sua superfície, aumentando a absorção de luz do dispositivo. ${ }^{109-112}$

\section{Células solares de silício}

Os métodos comumente utilizados para aumentar a absorção de luz em células solares convencionais de primeira geração, como a texturização da superfície, ${ }^{113,114}$ não são adequados no caso de células que utilizam filmes finos como camada fotoativa, devido à dificuldade de aplicação da texturização em dimensões de poucos micrômetros. Além disso, estes métodos podem resultar em consideráveis perdas de recombinação devido ao aumento da superfície. ${ }^{115}$ Dentro deste contexto, a incorporação de NPs-M é uma alternativa promissora para melhorar a eficiência destes dispositivos.

Schaadt et al. ${ }^{116}$ foram os pioneiros no estudo do efeito LSPR em uma célula solar de primeira geração, com junção $p n$ de silício, através da incorporação de NPAu esféricas na superfície do semicondutor. Neste trabalho, os autores observaram um aumento na amplitude do campo elétrico e no tempo de interação do campo com o material semicondutor, resultando em maior absorção da luz incidente quando comparada com uma célula de referência sem NPs. Como consequência, ocorreu um aumento na geração de fotocorrente em comprimentos de onda correspondentes ao da LSPR das NPAu.

Pillai et al. ${ }^{117}$ investigaram os efeitos de plasmons de superfície em células solares de primeira e segunda geração à base de silício. NPAg de diferentes tamanhos foram adicionadas, sendo observado que as partículas maiores respondem de maneira mais efetiva em comprimentos de onda maiores e partículas de menores dimensões mostram melhor absorção na região do visível. Para as células de primeira geração, que utilizam wafer de silício, o aumento da absorção na região do visível não foi significativo. Uma das razões para explicar este resultado é que células mais espessas já absorvem fortemente no visível e, portanto, o efeito dos plasmons não foi significativo, diferentemente do que ocorre no caso das células de filmes finos de silício. Os autores constataram que ocorre a melhora da absorção e reflexão interna da luz em ambos dispositivos perto da banda proibida do silício, que seria uma alternativa para melhorar a eficiência destas células solares. Adicionalmente, os autores verificaram que o efeito LSPR deve contribuir para qualquer material semicondutor em que o intervalo da banda de energia seja menor do que a frequência de ressonância dos plasmons.

A influência da LSPR também foi investigada em células solares de silício cristalino (c-Si) através da adição de NPs esféricas de diferentes metais (como Al, $\mathrm{Cu}, \mathrm{Ag}$ e Au). As NPs plasmônicas localizadas próximas à superfície da célula espalharam de forma eficiente a luz incidente para o interior do dispositivo. ${ }^{118}$ Os autores observaram que NPs de Al apresentam melhor transmissão da luz ao longo de quase todo o espectro solar, podendo ser uma alternativa eficiente e de baixo custo para utilização do efeito LSPR na produção em larga escala de células solares de silício cristalino.

Outra abordagem foi sugerida para explorar o efeito LSPR nas células solares, consistindo na redução da reflexão de luz utilizando uma superfície de silício texturizada, com a qual se obteve uma redução máxima na reflexão de $8 \%$ utilizando NPAg com tamanho de $100 \mathrm{~nm} .{ }^{119}$ Os autores concluíram que as NPAg (em nano escala) e a superfície de silício texturizada (em microescala) melhoram os parâmetros fotovoltaicos, como a tensão de circuito aberto (indiferente ao tamanho e morfologia das NPs), o fator de preenchimento, a resistência em série e a fotocorrente (sensível ao tamanho das NPs), resultando em um aumento da eficiência da conversão de 4,49\% para $6,42 \%$ em uma grande área do dispositivo de $12,24 \mathrm{~cm}^{2}$.

Pesquisas mais recentes, ${ }^{120}$ que também usaram células solares com a superfície texturizada de silício cristalino, além de $\mathrm{TiO}_{2}$ para separar as camadas do semicondutor, fizeram a comparação entre o efeito LSPR através da adição de NPAg e nanopartículas de índio. A união das NPs com o processo de texturização dos dispositivos resultou em maior aumento da absorção e também da densidade de corrente de curto-circuito $\left(\mathrm{J}_{\mathrm{sc}}\right)$. Com a incorporação das NPs de índio houve um aumento da eficiência em $13,01 \%$ e um aumento na $\mathbf{J}_{\mathrm{sc}}$ em $8,64 \%$, enquanto que com a incorporação das NPAg o aumento na eficiência foi de $9,56 \%$ e um aumento da $\mathbf{J}_{\mathrm{sc}}$ de $4,71 \%$ (comparação com uma célula solar sem modificações; sem NPs e texturização). As melhores respostas com as NPs de índio foram atribuídas à larga banda de dispersão plasmônica deste material.

\section{Célula solar orgânica}

A maior desvantagem das células solares orgânicas em relação às de silício ainda é a baixa eficiência de conversão de energia (máximos ca. $11 \%$ ) e a pouca estabilidade ao longo do tempo. ${ }^{121,122} \mathrm{~A}$ eficiência é limitada principalmente pela baixa mobilidade dos portadores de carga e absorção em pequena faixa do espectro solar. Com o objetivo de aumentar a eficiência destes dispositivos, a camada fotoativa tem sido objeto de intenso estudo. ${ }^{123}$ Assim como nas células à base de silício, o aprisionamento da luz é uma alternativa promissora para uma maior absorção de luz, resultando em maiores eficiências. Para aumentar a absorção destes dispositivos tem sido proposto o uso de nanoestruturas plasmônicas principalmente de $\mathrm{Ag}$ e $\mathrm{Au} .{ }^{123}$

Para aumentar a absorção das células orgânicas, Kim et al. ${ }^{124}$ incorporaram NPAg através de eletrodeposição no eletrodo transparente, tendo como camada de bloqueio poli(estireno sulfonado de sódio): poli(3,4-etileno dioxitiofeno) (PSS:PEDOT) em contato direto com 
a heterojunção de poli(3hexiltiofeno):fulereno 1-(3-metoxicarbonil)-propil-1-fenil-(6,6) $\mathrm{C}_{61}(\mathrm{P} 3 \mathrm{HT}: \mathrm{PCBM})$. A eficiência dos dispositivos aumentou de $3,05 \%$ para $3,69 \%$, decorrente principalmente do aumento da densidade de fotocorrente, como resultado da maior absorção na camada fotoativa, devido ao aumento do campo elétrico nas vizinhanças das NPs pela LSPR. No trabalho de Kalfagiannis et $a l .,{ }^{121}$ foram incorporadas NPAg em duas regiões distintas de uma célula orgânica de heterojunção P3HT:PCBM: i) no topo do ânodo transparente e ii) no topo da camada fotoativa. O melhor desempenho global foi apresentado pelo dispositivo com as NPs no topo do ânodo transparente, com um aumento de $17 \%$ na eficiência. Com a introdução das NPs no topo da camada ativa, o dispositivo apresentou um aumento em $25 \%$ na $\mathrm{J}_{\mathrm{sc}}$, porém, com resultados inferiores para resistência em série. Os autores constataram que há melhor dispersão de luz em regiões não-especulares quando a luz encontra as NPs após a camada fotoativa, e também, quando colocadas nesta posição, as NPs auxiliam na condução das lacunas até o ITO. Ambos os fatores levaram à melhoria na eficiência.

Noh et al. ${ }^{123}$ demonstraram o efeito plasmônico em uma célula orgânica de heterojunção P3HT:PCBM através da inserção de nanoprismas de Ag na camada de bloqueio composta por PEDOT:PSS. Foram estudados os efeitos LSPR variando o tamanho e a distância dos nanoprismas em relação à camada ativa P3HT:PCBM. As características fotovoltaicas mostraram que a maior eficiência de conversão estava relacionada ao aumento da $\mathrm{J}_{\mathrm{sc}}$, e que esta melhora está diretamente relacionada com o aumento da absorção óptica pela inserção dos nanoprismas. Além disso, observaram a melhora das características fotovoltaicas quando a distância entre os nanoprismas e camada ativa era mínima, sugerindo que o aumento da fotocorrente e da absorção óptica ocorreu devido ao aumento do campo elétrico; a luz incidente foi intensificada na camada ativa pela LSPR dos nanoprismas.

Jin et al. ${ }^{125}$ utilizaram uma célula orgânica com configuração invertida, sendo inserida uma camada de bloqueio de lacunas (batocupraína, BCP) entre o ITO e a camada ativa, e uma camada de bloqueio de elétrons $\left(\mathrm{MoO}_{3}\right)$ entre a camada ativa e o cátodo (alumínio). A camada ativa foi composta pelo material doador tetrafenil-dibenzo-periflanteno (DBP) e material aceitador $\mathrm{C}_{60}$. Foram depositadas NPAg na camada de bloqueio BCP através do processo de evaporação térmica para que houvesse um maior aproveitamento da luz pela LSPR. Os autores observaram que a célula invertida apresentou um aumento na eficiência de $33 \%$ após a inserção das NPAg, apresentando uma eficiência de $4,87 \%$. Este aumento foi atribuído à melhoria das propriedades elétricas e ao aumento da absorção de luz em virtude da superfície modificada do ITO com as NPs. Os resultados forneceram uma nova abordagem de utilização das NPs, que também podem ser introduzidas na camada de bloqueio em células orgânicas invertidas, utilizando uma deposição relativamente simples.

Liu et al. ${ }^{126}$ descreveram o efeito plasmônico através da incorporação de NPAg de diferentes tamanhos na camada de bloqueio $(20 \mathrm{~nm})$ de PEDOT:PSS e na camada ativa $(7 \mathrm{~nm})$. A camada de bloqueio foi duplamente depositada para reduzir a rugosidade e, assim, melhorar as propriedades elétricas pelo melhor contato. Com esta configuração, o dispositivo apresentou uma eficiência de conversão de $9,2 \%$, o que representa uma melhoria de 21,7\% em relação às células orgânicas padrão. Estes resultados sugerem uma nova abordagem para alcançar uma melhoria global dos dispositivos através do efeito de ressonância dupla pelas NPs.

Notarianni et al. ${ }^{127}$ estudaram os diferentes métodos de produção e incorporação das NPAu no dispositivo, verificando que a absorção é influenciada diretamente pela concentração, tamanho, geometria e principalmente a localização das NPs no interior da célula solar.
As melhores respostas foram obtidas com a utilização de um filme fino de NPAu depositado diretamente sobre o ITO, resultando em aumento de $10 \%$ na eficiência devido à melhora na absorção de luz através do aumento da secção transversal de dispersão de luz dentro do dispositivo e da intensificação do campo elétrico, sem a necessidade de aumentar a espessura da camada ativa.

Com a incorporação de diferentes concentrações de NPAu em um filme de P3HT em uma célula orgânica, Antoni et al. ${ }^{4}$ investigaram os efeitos da LSPR sobre a estabilidade estrutural e óptica do filme de P3HT. As NPAu foram depositadas entre o substrato de ITO e o filme de P3HT. Os autores observaram um aumento da absorção de luz da camada de P3HT na região do visível e um maior aprisionamento da luz dentro do filme, mas apenas com a adição de grandes concentrações de material plasmônico. Com o monitoramento da fotodegradação do material, observaram uma melhoria da estabilidade estrutural e óptica na presença das NPAu, aumentando o tempo de vida e a capacidade do dispositivo em converter luz em energia elétrica. Também observaram que as NPAu atuaram como um filtro óptico durante a irradiação e que a melhoria nas características das células depende da eficiência do acoplamento das linhas do campo elétrico, sendo fortemente afetada pela distância entre a incorporação das NPs no dispositivo.

\section{Célula solar sensibilizada por corante (DSSC)}

Hou et al. estudaram o efeito de materiais plasmônicos em DSSCs utilizando três configurações diferentes: incorporando $\mathrm{NPAu}_{\text {no }} \mathrm{TiO}_{2}$ e uma camada do corante N719 recobrindo toda a estrutura, na segunda configuração as NPAu foram depositadas como ilhas no topo da camada de $\mathrm{TiO}_{2}$ e o corante recobriu a superfície da estrutura, e na terceira configuração o corante foi depositado na camada de $\mathrm{TiO}_{2}$ e depois as NPAu foram depositadas também como ilhas no topo da estrutura. ${ }^{128}$ Os autores observaram que a primeira configuração apresentou melhor desempenho em comparação às demais, apresentando um aumento de 2-4 vezes na eficiência de conversão sob iluminação de luz na região do visível comparado com a célula de referência, sem adição de NPs. A segunda e a terceira configurações apresentaram resultados inferiores ao do dispositivo sem as NPs. Os autores atribuíram esta ineficiência à redução da área de contato entre o $\mathrm{TiO}_{2}$ e o corante (segunda configuração) ou pela redução da área da superfície de $\mathrm{TiO}_{2} /$ corante exposta à luz (terceira configuração). Assim, concluíram que o melhor desempenho da DSSC é dependente da configuração geométrica das NPAu, do corante e do eletrodo de trabalho de $\mathrm{TiO}_{2}$.

Lin et al. ${ }^{129}$ descreveram a obtenção de DSSC utilizando NPAg com duas configurações distintas: na primeira as NPs foram depositadas sobre o filme de $\mathrm{TiO}_{2}\left(\mathrm{FTO} / \mathrm{TiO}_{2} / \mathrm{NPAg}\right)$ e na segunda as NPs foram depositadas entre o substrato de óxido de estanho dopado com flúor (FTO) e a camada de $\mathrm{TiO}_{2}\left(\mathrm{FTO} / \mathrm{NPAg} / \mathrm{TiO}_{2}\right)$. Ambas as configurações apresentaram alta absorção na região do visível com a incorporação das NPs, porém apresentaram diferentes propriedades fotovoltaicas. Foi observado que a célula com $\mathrm{FTO} / \mathrm{TiO}_{2} / \mathrm{NPAg}$ apresentou o maior aumento na fotocorrente comparado com a célula de referência sem as NPs e esta configuração contribuiu de forma mais efetiva para a dispersão da luz dentro do dispositivo. Os autores concluíram que o uso do material plasmônico altera as propriedades de absorção do material semicondutor circundante, melhorando a separação de cargas do corante.

O tamanho e a forma das NPs podem ser controlados a fim de sobrepor a banda de LSPR com as bandas de absorção dos corantes. Com esta finalidade, Kim et al. ${ }^{130}$ fabricaram nanopratos de $\mathrm{Ag}$, controlando tamanho e forma para que as bandas LSPR da Ag correspondessem com as duas bandas de absorção, na região do 
visível, do corante N719. Foram obtidos nanopratos com formas não uniformes, já que bordas e cantos pontiagudos em NPs metálicas podem gerar LSPR mais intensa quando comparadas com a forma esférica. A eficiência da DSSC foi afetada pela porcentagem em peso de nanopratos de $\mathrm{Ag}$ adicionados e pelo grau de sobreposição espectral entre as bandas de extinção dos nanopratos de Ag e as duas bandas de absorção do corante N719, centradas em 393 e 533 nm. Com a otimização da sobreposição e da quantidade de nanopratos, a eficiência na conversão de energia passou de $8,6 \%$ para $10,1 \%$. Menores eficiências foram obtidas para maiores adições de nanopratos por causa da agregação das estruturas, fazendo com que a LSPR dos nanopratos agregados tornassem-se incompatíveis com as duas bandas de absorção do corante.

O trabalho de Choi et al. ${ }^{131}$ estudou o efeito das NPs atuando na melhora das características da célula solar via LSPR ou via efeito de carregamento de elétrons. $\mathrm{O}$ foco do trabalho foi isolar cada um dos efeitos através da utilização de dispositivos com estrutura casca-núcleo de $\mathrm{SiO}_{2} / \mathrm{NPAu}$ e $\mathrm{TiO}_{2} / \mathrm{NPAu}$. $\mathrm{O} \mathrm{SiO}_{2}$ é um material isolante que atua como uma barreira para bloquear a carga dos elétrons do núcleo de metal, apresentando assim apenas o efeito LSPR das NPs no dispositivo. Por outro lado, o $\mathrm{TiO}_{2}$ é um semicondutor e, portanto, é capaz de transferir elétrons para o núcleo de $\mathrm{Au}$, apresentando o efeito de carregamento de elétrons. Tanto o $\mathrm{SiO}_{2} / \mathrm{NPAu}$ quanto $\mathrm{TiO}_{2} /$ NPAu apresentaram melhores eficiência de conversão de energia em comparação a uma DSSC de referência (com $\mathrm{TiO}_{2}$ apenas), sendo 9,29\% para a referência, 9,78\% para $\mathrm{TiO}_{2}+\mathrm{e} \mathrm{TiO}_{2} / \mathrm{NPAu}$ e $10,21 \%$ para $\mathrm{TiO}_{2}+\mathrm{SiO}_{2} / \mathrm{NPAu}$. Concluíram que os efeitos da LSPR aumentam a fotocorrente, enquanto que os efeitos de carregamento levam a melhoria da fotovoltagem.

Também usando uma estrutura casca-núcleo, Jang et al. ${ }^{132}$ desenvolveram uma DSSC com NPAu em duas configurações distintas: i) na primeira configuração as NPAu foram depositadas no núcleo de $\mathrm{SiO}_{2}$ e revestidas com $\mathrm{TiO}_{2}$ e ii) na segunda, $\mathrm{SiO}_{2}$ ainda como núcleo e a deposição das NPAu ocorreu na casca de $\mathrm{TiO}_{2}$. Os autores estudaram diferentes espessuras e concentrações tanto de NPs como da estrutura casca-núcleo. Observaram melhora do desempenho do dispositivo em relação a uma referência casca-núcleo de $\mathrm{SiO}_{2} / \mathrm{TiO}_{2}$ sem NPs. A estrutura de $\mathrm{SiO}_{2}(\mathrm{NPAu}) / \mathrm{TiO}_{2}$ apresentou um aumento na eficiência de conversão de energia de ca. $10 \%$ e com a estrutura de $\mathrm{SiO}_{2} / \mathrm{TiO}_{2}(\mathrm{NPAu})$ o aumento foi de ca. $14 \%$ em comparação à referência. Na configuração em que as NPs ficam no núcleo de $\mathrm{SiO}_{2}$, passam a apresentar maior estabilidade, já que ficam protegidas do contato com o eletrólito que pode levar a oxidação e, como o campo elétrico induzido pelas NPAu fica blindado dentro desta estrutura, a melhoria na eficiência é menos acentuada. Mesmo sendo estruturas muito parecidas, a distância de interação do corante com a NP na primeira configuração é menor, isto leva a maior excitação das moléculas do corante pelo aumento do campo elétrico causado pela LSPR das NPAu e, consequentemente, uma maior eficiência.

Kim et al. ${ }^{133}$ estudaram a eficiência de DSSC baseada em uma dupla camada de filme de $\mathrm{TiO}_{2} / \mathrm{NPAg}$ e $\mathrm{TiO}_{2} / \mathrm{NPAu}$. As NPAg têm absorção LSPR em torno de $390 \mathrm{~nm}$, enquanto que as NPAu têm sua absorção LSPR perto de $530 \mathrm{~nm}$, sendo ambas correlacionadas com as distintas regiões de absorção do corante N719. A eficiência da conversão de energia usando a dupla camada com as NPs passou de $8,42 \%$ para $10,03 \%$, sendo um valor muito próximo com o valor mais alto já encontrado para DSSC com LSPR. ${ }^{131}$

No trabalho de Oliveira et al. ${ }^{5}$ o efeito da LSPR foi estudado com a incorporação de NPAu em DSSC com duas configurações distintas: i) na primeira as NPAu foram colocadas entre o semicondutor e o corante $\left(\mathrm{TiO}_{2} / \mathrm{NPAu} /\right.$ corante) e ii) na segunda configuração as NPAu foram colocadas sobre o semicondutor que já estava sensibilizado pelo corante $\left(\mathrm{TiO}_{2} /\right.$ corante/NPAu). Com a incorporação das NPAu às DSSC apresentaram melhores valores de IPCE, porém, valores menores de fator de preenchimento quando comparados com uma DSSC padrão sem a influência da LSPR. A melhoria na fotocorrente foi relacionada com a combinação de fatores, como o aumento do campo elétrico induzido e o melhor espalhamento de luz. A melhoria na eficiência é dependente da configuração da DSSC, assim, quando as NPAu foram incorporadas diretamente na superfície do $\mathrm{TiO}_{2}$, as DSSC apresentaram maior eficiência devido a maior densidade de elétrons fotoexcitados que foram transferidos no sentido da banda de condução de $\mathrm{TiO}_{2}$. Para explicar o valor de fotocorrente inferior da configuração $\mathrm{TiO}_{2}$ /corante/NPAu os autores sugeriram dois efeitos: uma menor quantidade de moléculas do corante é afetada pela LSPR das NPAu e uma menor quantidade de elétrons fotoexcitados das NPAu pode ser transferida para a banda de condução do $\mathrm{TiO}_{2}$ devido à camada de potencial gerada pelas moléculas do corante.

\section{Célula solar sensibilizada por quantum dots (QDSC)}

Com o objetivo de desenvolver QDSC com maior eficiência, Kumar et al. ${ }^{134}$ introduziram $\mathrm{NPAg}$ sobre $\mathrm{TiO}_{2}$ com posterior introdução do QD de CdS. As QDSCs foram montadas utilizando eletrólitos líquido e gel com $\mathrm{S}^{2-}$ como espécie iônica e nanotubos de carbono com multicamadas como contra eletrodo. Foram preparadas quatro configurações diferentes: utilizando eletrólito líquido (com e sem NPAg) e utilizando eletrólito gel (com e sem NPAg), e foram introduzidas simultaneamente no dispositivo diferentes morfologias de nanoestruturas: NPs e nanobastões (NBs) de Ag. Os autores não encontraram diferença significativa na utilização de eletrólito líquido ou gel no desempenho da célula, porém com a introdução das nanoestruturas a QDSC apresentou eficiência ligeiramente maior com a utilização do eletrólito líquido, passando de 2,90\% para 4,27\% em eficiência. Concluiu-se que, assim como nos demais tipos de células solares, a incorporação de NPs com efeito LSPR aumenta o desempenho da célula através da maior absorção e melhor espalhamento interno da luz no dispositivo. Os autores demonstraram que com a utilização de nanoestruturas de diferentes formas, as QDSC apresentaram uma alta eficiência considerando o pouco tempo de estudo da utilização desse tipo de tecnologia com QD e a pouca informação sobre a introdução de estruturas plasmônicas.

Lu et al. ${ }^{135}$ propuseram em seu trabalho o aumento da absorção do fóton, explorando o aprisionamento da luz através da incorporação de NPAg na parte anterior de uma QDSC com a junção de InGaAs/GaAs. A posição de inserção das NPs foi ajustada para que apenas a luz com comprimentos de ondas maiores (com energia mais baixa que a banda proibida da camada de GaAs) que não foi completamente absorvida na célula solar possa interagir com as NPs e ser espalhada de volta para dentro do dispositivo, resultando em aumento do comprimento do percurso. Os autores demonstraram que a introdução das NPAg resultou em um aumento simultâneo em $5,3 \%$ na $J_{\text {sc }}$ e um aumento de $0,9 \%$ na $V_{\text {oc }}$ quando comparadas com uma célula de referência. A eficiência de conversão de energia apresentou uma melhora de $7,6 \%$.

Com o objetivo de aproveitar a luz incidente na região do infravermelho próximo, que corresponde a $40 \%$ da energia do sol, Kawawaki et al. ${ }^{136}$ preparam QDSC avaliando o efeito plasmônico com a adição de NPAu. Neste estudo foi montada uma célula composta por QD de $\mathrm{PbS}$ depositados sobre filme fino de $\mathrm{TiO}_{2}$ e um substrato de ITO, com posterior deposição de NPAu. A fotocorrente do eletrodo com as NPAu apresentou valor significativamente maior do que o eletrodo sem as NPs. Na ausência do QD, montando um dispositivo com configuração ITO/NPAu/TiO ${ }_{2}$, os autores encontraram valores desprezíveis de fotocorrente. Embora muitas vezes a separação de carga induzida pelo plasmon seja observada na interface de $\mathrm{TiO}_{2} / \mathrm{NPAu}$, neste caso 
a espessura do filme utilizada era muito fina, não influenciando no aumento da fotocorrente, portanto, o aumento de fotocorrente foi atribuído apenas ao efeito LSPR das NPAu na presença dos QDs. Adicionalmente, foi observado um aumento gradual na fotocorrente com a aproximação das NPAu devido a intensificação do campo elétrico. Quando o espaçamento se tornou muito curto houve queda da fotocorrente, que foi atribuída à transferência de energia ressonante do QD excitado para as NPs antes que ocorresse a transferência dos elétrons dos QDs para a banda de condução do $\mathrm{TiO}_{2}$. Os autores concluíram que os melhores resultados para este tipo de célula se dá pelo uso de QDs pequenos separados por uma distância intermediária de NPAu, também de pequeno tamanho.

Kawawaki et al. ${ }^{137}$ também preparam QDSC com fotocorrente e eficiência mais elevada, sem que aumentasse a espessura da camada do QD (esta aumentaria a resistência em série interna do dispositivo). Assim, avaliaram o efeito LSPR da adição de NCs de Ag em uma QDSC com heterojunção de QD PbS / nanofios de ZnO. Com a introdução dos NCAg observaram uma forte dispersão do campo elétrico na borda das nanoestruturas e um aumento da absorção. A fotocorrente das QDSC foi reforçada pelos NCAg, especialmente na região de 700-1200 nm devido ao aumento da absorção de luz pelo efeito da LSPR e possível facilitação da dissociação do éxciton. Através da otimização de posição e quantidade de NCAg nas células com heterojunção $\mathrm{PbS} / \mathrm{ZnO}$, a eficiência de conversão de energia passou de $4,45 \%$ para $6,03 \%$.

Utilizando como material semicondutor uma matriz de nanobastões de $\mathrm{ZnO}$ sensibilizada por QDCdS, Eskandari et al. ${ }^{138}$ adicionaram NPAg para avaliar o efeito da LSPR na melhora do desempenho da célula solar. As características do dispositivo, como a $V_{o c}, J_{s c}$ o fator de preenchimento e a eficiência de conversão, aumentaram em função da porcentagem de NPAg até a adição de $5 \%$, sendo que após esta quantidade a resposta começou a diminuir. Esta melhora foi atribuída ao maior espalhamento da luz no interior do dispositivo com a incorporação das NPAg. Também foi observado um campo elétrico mais forte em torno das NPs devido ao efeito LSPR. Assim, quando os QDs são colocados próximos às NPs-M, eles interagem tanto com a luz incidente quanto com o campo elétrico induzido devido ao plasmon; esta interação colabora com o aumento da fotocorrente pelos elétrons excitados dos QDs. Os autores atribuíram o aumento inicial da $\mathrm{V}_{\mathrm{oc}}$ pela redução dos defeitos na superfície dos nanobastões de $\mathrm{ZnO}$ à introdução das NPAg, causando a diminuição da recombinação dos pares de elétrons-buracos. Com um teor maior de NPs a $\mathrm{V}_{\mathrm{oc}}$ começa a diminuir pelo fato de que nem todas as NPs estão ligadas ao ZnO, podendo ser oxidadas pelo eletrólito. Assim, o teor de adição das NPs deve ser controlado dependendo da estrutura para que haja melhores resultados na fotoabsorção das QDSCs.

O efeito LSPR foi investigado para uma QDSC composta por InAs/GaAs através da adição de NPs de Au e de Ag em diferentes células. ${ }^{139} \mathrm{~A}$ fotocorrente foi notavelmente melhorada em ambas as células com a adição das NPs. No QDSC com NPAg a $\mathrm{J}_{\mathrm{sc}}$ apresentou um aumento mais elevado do que com NPAu. A eficiência de conversão de energia da QDSC de referência era de 8\%, com NPAg apresentou um valor de $9,5 \%$ e com as NPAu foi de $8,9 \%$. Porém o fator de preenchimento foi reduzido em ambas configurações devido ao aumento da resistência provocada pelos ligantes químicos utilizados para deposição das NPs. Os autores concluíram que ambas NPs (Ag e $\mathrm{Au}$ ) melhoram significativamente o desempenho do dispositivo devido a maior dispersão dos fótons e o aprisionamento por plasmons de superfície gerado das NPs. Adicionalmente, foi observado a interação entre os QDs e o efeito LSPR na região de comprimentos de onda próximo do infravermelho, sugerindo que a LSPR também melhora o desempenho dos QDs nas células solares.

\section{CONCLUSÕES}

As publicações mais recentes enfatizam as aplicações dos materiais plasmônicos, que só foram possíveis após a compreensão da natureza e do comportamento do efeito LSPR através de um extenso trabalho teórico e empírico desenvolvido por cerca de 100 anos. A aplicação da LSPR no desenvolvimento de sensores de alta sensibilidade, baixo limite de detecção e com potencial para miniaturização se deu com o entendimento da dependência entre a energia de propagação do LSPR com o índice de refração próximo à superfície nanoestruturada e com a distância entre as nanopartículas. Por outro lado, a obtenção de células solares com maiores eficiências ocorre devido a fenômenos de espalhamento e aprisionamento de luz, assim como da propagação da LSPR. Embora muitos tratamentos teóricos sejam realizados considerando como sistema modelo nanopartículas metálicas isoladas, os trabalhos mostrados nesta revisão deixam clara a necessidade da compreensão do efeito plasmônico em agregados para uma melhor previsão do comportamento destes materiais quando aplicados. Um dos pontos mais interessantes no estudo e aplicação do LSPR é a necessidade de pouca infraestrutura, uma vez que a literatura descreve inúmeras rotas simples de síntese e caracterização destes materiais, tornando esta linha de pesquisa ainda mais abrangente.

\section{AGRADECIMENTOS}

Os autores A.Thesing, F. Tavares, J. Griep e M. R. F. Rodrigues agradecem à CAPES pelas bolsas de mestrado e doutorado. J. F. L. Santos e M. J. L. Santos agradecem ao CNPq, FAPERGS, PPGQ, PGCiMat e UFRGS.

\section{REFERÊNCIAS}

1. Alivisatos, A. P.; Barbara , P. F.; Castleman, A. W.; Chang, J.; Dixon , D. A.; Klein , M. L.; McLendon, G. L.; Miller, J. S.; Ratner, M. A.; Rossky, P. J.; Stupp, S. I.; Thompson, M. E.; Adv. Mater. 1998, 10, 1297.

2. Alivisatos, A. P.; J. Phys. Chem. 1996, 100, 13226.

3. Mulvaney, P.; Langmuir 1996, 12, 788.

4. De Antoni, L. O.; Loguercio, L. F.; Rodrigues, M. R. F.; Fernandes, J. A.; Ferreira, J.; Santos, M. J. L.; Polym. Degrad. Stab. 2016, 123, 62.

5. Oliveira, M. C.; Fraga, A. L. S.; Thesing, A.; Andrade, R. L.; Santos, J. F. L.; Santos, M. J. L.; J. Nanomater. 2015, 2015, 9.

6. Loguercio, L. F.; Alves, C. C.; Thesing, A.; Ferreira, J.; Phys. Chem. Chem. Phys. 2015, 17, 1234.

7. Fan, M.; Lai, F. J.; Chou, H. L.; Lu, W. T.; Hwang, B. J.; Brolo, A. G.; Chem. Sci. 2013, 4, 509.

8. Shaw, C. P.; Fan, M.; Lane, C.; Barry, G.; Jirasek, A. I.; Brolo, A. G.; J. Phys. Chem. C 2013, 117, 16596.

9. Hunt, L. B.; Gold Bull. 1976, 9, 134.

10. Wagner, F. E.; Haslbeck, S.; Stievano, L.; Calogero, S.; Pankhurst, Q. A.; Martinek, K.-P.; Nature 2000, 407, 691.

11. Faraday, M.; Philos. Trans. R. Soc. London. 1857, 147, 145.

12. Martins, M. A.; Trindade, T.; Quim. Nova 2012, 35, 1434.

13. Edwards, P. P.; Thomas, J. M.; Angew. Chem., Int. Ed. 2007, 46, 5480.

14. Turkevich, J.; Stevenson, P. C.; Hillier, J.; Discuss. Faraday Soc. 1951, 11,55 .

15. Frens, G.; Nature Phys. Sci. 1973, 241, 20.

16. Stauffer, R. C.; Isis 1957, 48, 33.

17. Maxwell, J. C.; Philos. Trans. R. Soc. London. 1865, 155, 459.

18. Jeszenszky, S.; IEEE Trans. Antennas Propag. 2011, 53, 221.

19. Cichon, D. J.; Wiesbeck, W.; Proceedings of the 1995 International Conference on 100 Years of Radio, Londres, 1995 (doi: 10.1049/ cp:19950782).

20. Horvath, H.; J. Quant. Spectrosc. Radiat. Transfer. 2009, 110, 787. 
21. Lock, J. A.; Gouesbet, G.; J. Quant. Spectrosc. Radiat. Transfer. 2009, 110,800 .

22. Greenberg, J. M.; Wang, R. T.; Bangs, L.; Nature Phys. Sci. 1971, 230, 110.

23. Ghosh, S. K.; Pal, T.; Chem. Rev. 2007, 107, 4797.

24. Kolwas, K.; Derkachova, A.; Shopa, M.; J. Quant. Spectrosc. Radiat. Transfer. 2009, 110, 1490.

25. Olson, J.; Dominguez-Medina, S.; Hoggard, A.; Wang, L. Y.; Chang, W. S.; Link, S.; Chem. Soc. Rev. 2015, 44, 40

26. Fan, X.; Zheng, W.; Singh, D. J.; Light: Sci Appl. 2014, 3, 179.

27. Link, S.; El-Sayed, M. A.; Int. Rev. Phys. Chem. 2000, 19, 409.

28. Hövel, H.; Fritz, S.; Hilger, A.; Kreibig, U.; Vollmer, M.; Phys. Rev. B 1993, 48, 18178.

29. Chang, W. S.; Willingham, B.; Slaughter, L. S.; Dominguez-Medina, S.; Swanglap, P.; Link, S.; Acc. Chem. Res. 2012, 45, 1936.

30. Catchpole, K. R.; Polman, A.; Appl. Phys. Lett. 2008, 93, 191113.

31. Olmon, R. L.; Slovick, B.; Jonhson, T. W.; Shelton, D.; Oh, S. H.; Boreman, G. D.; Raschke, M. B.; Phys. Rev. B 2012, 86, 235147.

32. Pinchuk, A.; Kreibig, U.; Hilger, A.; Surf. Sci. 2004, 557, 269.

33. Kreibig, U.; Bour, G.; Hilger, A.; Gartz, M.; Phys. Status Solidi A 1999, $175,351$.

34. Persson, B. N. J.; Surf. Sci. 1993, 281, 153

35. Liu, S.-Y.; Huang, L.; Li, J.-F.; Wang, C.; Li, Q.; Xu, H.-X.; Guo, H.-L.; Meng, Z.-M.; Shi, Z.; Li, Z.-H.; J. Phys. Chem. C 2013, 117, 10636.

36. Noguez, C.; J. Phys. Chem. C 2007, 111, 3806.

37. Menegotto, T., Pereira, M. B.; Correia, R. R. B.; Horowitz, F.; Appl. Opt. 2011, 50, 27.

38. Garnett, J. C. M.; Philos. Trans. R. Soc., A 1904, 203, 385.

39. Park, W.; Nano Convergence 2014, 1, 2.

40. Hirosige, T.; Historical Studies in the Natural Sciences 1969, 1, 151.

41. Jain, P. K.; El-Sayed, M. A.; J. Phys. Chem. C 2007, 111, 17451

42. Pockrand, I.; Swalen, J. D.; Gordon, J. G.; Philpott, M. R.; Surf. Sci. 1978, 74, 237.

43. Gordon, J. G.; Ernst, S.; Surf. Sci. 1980, 101, 499.

44. Nylander, C.; Liedberg, B.; Lind, T.; Sens. Actuators, B 1982, 3, 79.

45. Liedberg, B.; Nylander C.; Lundström, I.; Biosens. Bioelectron. 1995, 10, R1.

46. Nyholm, T.; Andäng, M.; Bandholtz, A.; Maijgren, C.; Persson, B.; Hotchkiss, G.; Fehniger, T. E.; Larsson, S.; Ährlund-Richter, L. J.; J. Biochem. Biophys. Methods 2000, 44, 41

47. Tsoi, P. Y.; Yang, J.; Sun, Y.-T.; Sui, S.-F.; Yang, M.; Langmuir 2000, 16, 6590 .

48. Nelson, B. P.; Grimsrud, T. E.; Liles, M. R.; Goodman, R. M.; Corn, R. M.; Anal. Chem. 2001, 73, 1 .

49. Dyr, J. E.; Rysavá, J.; Suttnar, J.; Homola, J.; Tobiska, P.; Sens. Actuators, B 2001, 74, 69 .

50. Quinn, J. G.; O'Neill, S.; Doyle, A.; McAtammey, C.; Diamond, D.; MacCraith, B. D.; O'Kennedy, R.; Anal. Biochem. 2000, 281, 135.

51. Webster, C. I.; Cooper, M. A.; Packman, L. C.; Williams, D. H.; Gray, J. C.; Nucleic Acids Res. 2000, 28, 1618.

52. Carvalho, R. M.; Rath, S.; Kubota, L. T.; Quim. Nova 2003, 26, 97.

53. Soares, J. C.; Shimizu, F. M.; Soares, A. C.; Caseli, L.; Ferreira, J.; Oliveira Jr, O. N.; ACS Appl. Mater. Interfaces 2015, 7, 11833

54. Silva, A. L. C. M.; Gutierres, M. G.; Thesing, A.; Lattuada, R. M.; Ferreira, J.; J. Braz. Chem. Soc. 2014, 25, 928.

55. Escobedo, C.; Chou, Y-W.; Rahman, M.; Duan, X.; Gordon, R.; Sinton, D.; Brolo, A. G.; Ferreira, J.; Analyst 2013, 138, 1450

56. Monteiro, J. P.; Carneiro, L. B.; Rahman, M. M.; Brolo, A.G.; Santos, M. J. L.; Ferreira, J.; Girotto, E. M.; Sens. Actuators, B 2013, 178, 366.

57. Ferreira, J.; Monteiro, J. P.; Sabat, R. G.; Rochon, P.; Santos, M. J. L.; Girotto, E. M. Sens. Actuators, B 2012, 174, 270

58. Menezes, J. W.; Ferreira, J.; Santos, M. J.; Cescato, L.; Brolo, A. G.; Adv. Funct. Mater. 2010, 20, 3918.
59. Ferreira, J. ; Santos, M. J. L. ; Rahman, M. M. ; Brolo, A. G.; Gordon, R.; Sinton, D.; Girotto, E. M.; J. Am. Chem. Soc. 2009, 131, 436.

60. Eftekhari, F.; Gordon, R.; Ferreira, J.; Brolo, A. G.; Sinton, D.; Appl. Phys. Lett. 2008, 92, 253103.

61. Eftekhari, F.; Escobedo, C.; Ferreira, J.; Duan, X.; Girotto, E. M.; Brolo, A. G.; Gordon, R.; Sinton, D.; Anal. Chem. 2009, 81, 4308.

62. Brolo, A.; Nat. Photonics. 2012, 6, 709.

63. Vidotti, M; Carvalhal, R. F.; Mendes, R. K.; Ferreira, D. C. M.; Kubota, L. T.; J. Braz. Chem. Soc. 2011, 22, 3.

64. Heaton, R. J.; Peterson, A. W.; Georgladis, R. M.; Proc. Natl. Acad. Sci. U. S. A. 2001, 98, 3701.

65. Valsecchi, C.; Brolo, A. G.; Langmuir 2013, 29, 5638.

66. Thesing, A.; Loguercio, L. F.; Santos, M. J. L.; Ferreira, J.; J. Nanosci. Nanotechnol. 2016, no prelo.

67. Choi, J.; Choi, M-J.; Yoo, J-K.; Park, W-I.; Lee, J. H.; Lee, J. Y.; Jung, Y. S.; Nanoscale 2013, 5, 7403.

68. Petryayeva, E.; Krull, U. J.; Anal. Chim. Acta 2011, 706, 8.

69. Chung, T. L., S-Y.; Song, E-Y.; Chun, H.; Lee, B.; Sensors 2011, 11, 10907.

70. Schneider, C. S.; Bhargav, A. G.; Perez, J. G.; Wadajkar, A. S.; Winkles, J. A.; Woodworth, G. F.; Kim, A. J.; J. Controlled Release 2015, 219 , 331.

71. Zhou, B.; Xiao, X.; Liu, T.; Gao, Y.; Huang, Y.; Wen, W; Biosens. Bioelectron. 2016, 77, 385.

72. Fan, M.; Andrade, M. L.; Thompson, M.; Brolo, A. G.; Anal. Chem. 2010, 82,6350

73. Bahrami, F.; Alam, M. Z.; Aitchison, J. S.; Mojahedi, M.; Plasmonics 2012, 8,465

74. Homola, J.; Chem. Rev. 2008, 108, 462.

75. Zhou, W.; Ma, Y.; Yang, H.; Ding, Y.; Luo, X.; Int. J. Nanomed. 2011, 6, 381.

76. Shin, D. O.; Jeong, J.-R.; Han, T. H.; Koo, C. M.; Park, H.-J.; Lim, Y. T.; Kim, S. O.; J. Mater. Chem. 2010, 20, 7241.

77. Shen, Y.; Zhou, J.; Liu, T.; Tao, Y.; Jiang, R.; Liu, M.; Xiao, G.; Zhu, J.; Zhou, Z-K.; Wang, X.; Jin, C.; Wang, J.; Nat. Commun. 2013, 4, 2381.

78. Dmitriev, A.; Hagglund, C.; Chen, S.; Fredriksson, H.; Pakizeh, T.; Kall, M.; Sutherlan, D. S.; Nano Lett. 2008, 8, 3893.

79. Cao, J.; Galbraith, E. K.; Sun, T.; Grattan, K. T. V.; Sens. Actuators, B 2012, 169, 360

80. Jain, P. J.; Lee, K. S.; El-Sayed, I. H.; El-Sayed, M. A.; J. Phys. Chem. B 2006, 110, 7238 .

81. Steward, M. E.; Anderton, C. R.; Thompson, L. B.; Maria, J.; Gray, S K.; Rogers, J. A.; Nuzzo, R. G.; Chem. Rev. 2008, 108, 494.

82. Niedziolka-Jonsson, J.; Barka, F.; Castel, X.; Pisarek, M.; Bezzi, N.; Boukherroub, R.; Szunerits, S.; Langmuir 2010, 6, 4266.

83. Cha, H.; Yoon, J. H.; Yoon, S.; ACS Nano 2014, 8, 8554

84. Toma, H. E.; Zamarion, V. M.; Toma, S. H.; Araki, K.; J. Braz. Chem. Soc. 2010, 21, 1158

85. Jung, H.; Cha, H.; Lee, D.; Yoon, S.; ACS Nano 2015, 9, 12292.

86. Lee, D.; Yoon, S.; J. Phys. Chem. C 2015, 119, 7873.

87. Yoon, J. H.; Lim, J.; Yoon, S.; ACS Nano 2012, 6, 7199.

88. Zuloaga, J.; Prodan, E.; Nordlander, P.; Nano Lett. 2009, 9, 887.

89. Brown, L. V.; Sobhani, H.; Lassiter, J. B.; Nordlander, P.; Halas, N. J.; ACS Nano 2010, 4, 819.

90. Sobhani, A.; Manjavacas, A.; Cao, Y.; McClain, M. J.; Abajo, F. J. G.; Nordlander, P.; Halas, N. J.; Nano Lett. 2015, 15, 6946.

91. McClain, M. J.; Schlather, A. E.; Ringe, E. King, N. S.; Liu, L.; Manjavacas, A.; Knight, M. W.; Kumar, I.; Whitmire, K. H.; Everitt, H. O.; Nordlander, P.; Halas, N. J.; Nano Lett. 2015, 15, 2751.

92. Brongersma, M. L.; Halas, N. J.; Nordlander, P.; Nat. Nanotechnol. 2015, 10, 25

93. Link, S.; Burda, C.; Mohamed, M. B.; Nikoobakht, M.; El-Sayed, M. A.; Phys. Rev. B 2000, 61, 6086. 
94. Dong, P.; Lin, Y.; Deng, J.; Di, J.; Appl. Mater. Interfaces 2013, 5, 2392.

95. Hicks, E. M.; Zhang, X.; Zou, S.; Lyandres, O.; Spears, K. G.; Schatz, G. C.; Van Duyne, R. P.; J. Phys. Chem. B 2005, 109, 22351.

96. Vazquez-Mena, O.; Sannomiya, T.; Villanueva, L. G.; Voros, J.; Brugger, J.; ACS Nano 2011, 5, 844.

97. Marinakos, S. M.; Chen, S.; Chilkoti, A.; Anal. Chem. 2007, 79, 5278.

98. Nehl, C. L.; Liao, H. W.; Hafner, J. H.; Nano Lett. 2006, 6, 683.

99. Mock, J. J.; Smith, D. R.; Schultz, S.; Nano Lett. 2003, 3, 485.

100. Sherry, L. J.; Jin, R.; Mirkin, C. A.; Schatz, G. C; Van Duyne, R. P.; Nano Lett. 2006, 6, 2060.

101. Sherry, L. J.; Chang, S. H.; Schatz, G. C.; Van Duyne, R. P.; Wiley, B J.; Xia, Y. N.; Nano Lett. 2005, 5, 2034.

102. Kim, D-K.; Yoo, S-M.; Park, T-J.; Yoshikawa, H.; Tamiya, E.; Park, J. Y.; Lee, S-Y.; Anal. Chem. 2011, 83, 6215.

103. Manzano, M.; Vizzini, P. Jia, K.; Adam, P-M.; Ionescu, R. E.; Sens. Actuators, B 2016, 223, 295.

104. Zhang, D.; Sun, Y.; Wu, Q.; Ma, P.; Zhang, H.; Wang, Y.; Song, D.; Talanta 2016, 146, 364.

105. Li, H.; Guo, J.; Ping, H.; Liu, L.; Zhang, M.; Guan, F.; Sun, C.; Zhang, Q.; Talanta 2011, 87, 93.

106. Bharadwaj, R.; Mukherji, S.; Sens. Actuators, B 2014, 192, 804.

107. Kosaka, P. M.; Pini, V.; Ruz, J. J.; da Silva, R. A.; González, M. U.; Ramos, D.; Calleja, M.; Tamayo, J.; Nat. Nanotechnol. 2014, 9, 1047.

108. Atwater, H. A.; Polman, A.; Nat Mater. 2010, 3, 205.

109. Catchpole, K. R; Polman, A. Opt. Express. 2008, 16, 21793.

110. Almeida, L. C.; Zanoni, M. V. B.; J. Braz. Chem. Soc. 2014, 25, 579.

111. Tan, H.; Santbergen, R.; Smets, A. H. M.; Zeman, M.; Nano Lett. 2012, 12, 4070.

112. Pillai, S.; Green, M. A.; Sol. Energy Mater. Sol. Cells 2010, 94,1481.

113. Kuo, M. L.; Poxson, D. J.; Kim, Y. S.; Mont, F. W.; Kim, J. K.; Schubert, E. F.; Lin, S. Y.; Opt. Lett. 2008, 33, 2527.

114. Gangopadhyay, U.; Dhungel, S. K.; Basu, P. K.; Dutta, S. K.; Saha, H.; Yi, J.; Sol Energy Mater Sol. Cells 2007, 91, 285.

115. Beck, F.; Polman, A.; Catchpole, K. R.; J. Appl. Phys. 2009, 105, 114310.

116. Schaadt, D. M.; Feng, B.; Yu, E. T.; Appl. Phys. Lett. 2005, 86, 1.

117. Pillai, S.; Catchpole, K.; Trupke, T.; Green, M.A.; J. Appl. Phys. 2007, 101, 093105.

118. Singh, Y. P.; Jain, A.; Kapoor, A.; J. Sol. Energy. 2013, 2013, 1.
119. Sardana, S. K.; Chava, V. S. N.; Thouti, E.; Chander, N.; Kumar, S.; Reddy, S. R.; Komarala, V. K.; Appl. Phys. Lett. 2014, 104, 073903.

120. Ho, W. J.; Su, S. Y.; Lee, Y. Y.; Syu, H. J.; Lin, C. F.; Materials 2015, 8, 6668.

121. Kalfagiannis, N.; Karagiannidis, P. G.; Pitsalidis, C.; Panagiotopoulos, N. T.; Gravalidis, C.; Kassavetis, S.; Patsalas, P.; Logothetidis, S.; Sol. Energy Mater. Sol. Cells 2012, 104, 165.

122. Green, M. A.; Emery, K.; Hishikawa, Y.; Warta, W.; Dunlop, E. D.; Progress in Photovoltaics: Research and Applications 2015, 23, 1.

123. Noh, H. S.; Cho, E. H.; Kim, H. M.; Han, Y. D.; Joo, J.; Org. Electron. 2013, 14, 278.

124. Kim, S. S.; Na, S. I.; Jo, J.; Kim, D. Y.; Nah, Y. C.; Appl Phys Lett. 2008, 93,073307.

125. Jin, F.; Chu, B.; Li, W.; Su, Z.; Zhao, H.; Lee, C. S.; Opt. Express. 2014, $22,1669$.

126. Liu, X. H.; Hou, L. X.; Wang, J. F.; Liu, B.; Yu, Z. S.; Ma, L. Q.; Yang, S. P.; Fu, G. S.; Sol. Energy 2014, 110, 627.

127. Notarianni, M.; Vernon, K.; Chou, A.; Aljada, M.; Liu, J.; Motta, N.; Sol Energy. 2014, 106, 23.

128. Hou, W.; Pavaskar, P.; Liu, Z.; Theiss, J.; Aykol, M.; Cronin, S. B.; Energy Environ. Sci. 2011, 4, 4650.

129. Lin, S.; Lee, K.; Wu, J.; Wu, J.; Sol Energy. 2012, 86, 2600.

130. Kim, H. Y.; Rho, W. Y.; Lee, H. Y.; Park, Y. S.; Suh, J. S.; Sol. Energy 2014, 109, 61.

131. Choi, H.; Chen, W. T.; Kamat, P. V.; ACS Nano 2012, 6, 4418.

132. Jang, Y. H.; Jang, Y. J.; Kochuveedu, S. T.; Byun, M.; Lin, Z.; Kim, D. H.; Nanoscale 2014, 6, 1823.

133. Kim, H. Y.; Song, D. H.; Yoon, H.; Suh, J. S.; RSC Adv. 2015, 5, 27464.

134. Kumar, P.N.; Deepa, M.; Srivastava, A.K.; Phys. Chem. Chem. Phys. 2015, 17, 10040.

135. Lu, H. F.; Mokkapati, S.; Fu, L.; Jolley, G.; Tan H. H.; Jagadish, C.; Appl. Phys. Lett. 2012, 100, 2010.

136. Kawawaki, T.; Tatsuma, T.; Phys. Chem. Chem. Phys. 2013, 15, 20247.

137. Kawawaki, T.; Wang, H.; Kubo, T.; Saito, K.; Nakazaki, J.; Segawa, H.; Tatsuma, T.; ACS Nano 2015, 4, 4165.

138. Eskandari, M.; Ahmadi, V.; Yousefi rad, M.; Kohnehpoushi, S.; Phys. E 2015, 68, 202.

139. Wu, J.; Mangham, S. C.; Reddy, V. R.; Manasreh, M. O.; Weaver, B. D.; Sol. Energy Mater. Sol. Cells 2012, 102, 44. 